Kabiri, Ali, Liaghat, Gholamhossein, Alavi, Fatemeh, Ansari, Mehdi and Hedayati, Seyyed Kaveh. A comparative study of 3D printing and heat-compressing methods for manufacturing the thermoplastic composite bone fixation plate : design, characterization, and in vitro biomechanical experimentation. Proceedings of the Institution of Mechanical Engineers, Part H, Journal of Engineering in Medicine, 235(12), pp. 1439-1452. Copyright (C) 2021 IMechE. DOI: https://doi.org/10.1177/09544119211034353 


\title{
A comparative study of 3D printing and heat-compressing methods for manufacturing the thermoplastic composite bone fixation plate: Design, characterization, and in-vitro biomechanical experimentation
}

\author{
Ali Kabiri a, Gholamhossein Liaghat ${ }^{a}$, b, ${ }^{*}$, Fatemeh Alavia ${ }^{\text {a }}$, Mehdi Ansaric, Seyyed \\ Kaveh Hedayati ${ }^{\mathrm{a}}$ \\ ${ }^{a}$ Faculty of Mechanical Engineering, Tarbiat Modares University, Tehran, Iran

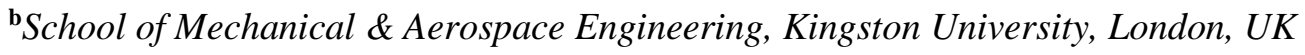 \\ 'Department of Mechanical Engineering, Arak University of Technology, Arak, Iran
}

\begin{abstract}
Metallic bone fixations, due to their high rigidity, can cause long-term complications. To alleviate metallic biomaterials' drawbacks, in this research new Glass Fiber/Polypropylene (GF/PP) composite internal fixations were developed, and an investigation of their mechanical behavior was performed through in-vitro biomechanical experiments. Short randomly oriented, long unidirectional prepreg, and long unidirectional fiber yarn were considered as reinforcements, and the effects on their mechanical properties of different manufacturing processes, i.e. 3D printing and heat-compressing, were investigated. The constructed fixation plates were tested in the transversely fractured diaphysis of bovine tibia under axial compression loading. The overall stiffness and the Von Mises strain field of the fixation plates were obtained within stable and unstable fracture conditions. The samples were loaded until failure to determine their failure loads, strains, and mechanisms. Based on
\end{abstract}

*Corresponding author: Gholamhossein Liaghat, Tarbiat Modares University, Jalal-e-Al-Ahmad, Tehran 14115111, Iran. Email: ghlia530@ modares.ac.ir, g.liaghat@ kingston.ac.uk 
the results, the GF/PP composite fixation plates can provide adequate interfragmentary movement to amplify bone ossification, so they can provide proper support for bone healing. Moreover, their potential for stress shielding reduction and their load-bearing capacity suggest their merits in replacing traditional metallic plates.

Keywords: Fixation plate, GF/PP composite, heat-compressing, 3D printing, In-vitro biomechanical test.

\section{Introduction}

Due to the lack of adequate support and compression in conservative treatments such as casts, especially at fracture sites, screws and plates are often employed for long bone fracture healing. The fixation plate provides immobilization for the bone's broken parts without causing tensile stress at the fracture site, while decreasing the fracture gap and accelerating the remodeling process [1].

Metallic fixation plates are usually made of 306 or 316 stainless steel, Cobalt-Chromium, or Titanium alloys. Due to their much higher modulus of elasticity (110-220 GPa [1]) compared to cortical bone (7-30 GPa [2]), their contribution to load-bearing in the bone neighborhood causes stress shielding. This effect delays the fracture healing process and can cause localized osteopenia beneath the plate. A significant number of re-fractures have been observed after removing the rigid metallic internal fixations; therefore, when removing metallic plates after fracture healing, additional protection must be provided to prevent weak bones re-fracturing at the fracture site. Hence, recent research has been focused on flexible fixation methods. Flexible fixation ideally provides adequate interfragmentary motion at the fracture site, which allows formed callus transformation into mature bone. There are two recommended approaches to increase the fracture fixation flexibility and reduce the stress shielding effect 
on the fracture site. These are a configuration change to the fixation plate structure and substitution of the fixation plate material.

Recently, the far cortical locking (FCL) technique was introduced to decrease structural stiffness of the fixture plate by changing the design of the screws and providing parallel interfragmentary motion, which results in the callus symmetrically forming around the fracture site. Furthermore, the FCL has good performance in the case of osteoporotic bone. The stability of non-contact locking plates compared to locking compression plates, (LCP) under static and dynamic loading, was investigated by Ahmad et al. [3]. The non-contact locking plate was found to provide more stability by increasing the distance between the fixation plate and the bone. They found that the optimum distance between the non-contact locking plate and the bone should be less than $2 \mathrm{~mm}$. Also, Bottlang et al. [4, 5] developed the FCL fixation plate to reduce locked plating structures' stiffness. They performed axial, torsional, four-point bending, and fatigue tests of the locked plate structure and compared them to the FCL structure implemented in femoral diaphysis. According to their results, the FCL reduces the axial structure stiffness and increases the torsional and bending strength of the healed bone. Hence, this strategy enhances the desired interfragmentary motion and improves the secondary stage of bone healing. Moazen et al. [6] determined the overall stiffness, fracture movement, failure strain, and the load of the FCL structure in stable and unstable fractures. They used FCL screws in a Sawbones fourth-generation composite femur and showed that the FCL could be an alternative fixation method to traditional methods. According to various studies, the FCL shows a slight decrease in axial structure strength but an increase in bending and torsional strength.

Changing of screw configuration could also be an approach to reduce the fixation plate systems' stiffness. For example, Yanez et al. [7] experimentally analyzed the cyclic compressive, flexural, and torsional behavior of a new screw configuration system made of 
biocompatible Polyether ether ketone (PEEK). This system acts as a lock nut and holds the end of the threaded screw shank which decreases the failure rate and has lower costs compared to conventional locking compression plates. Moreover, a novel dynamic plate with elastically suspended locking holes was presented by Tsai et al. [8], and its axial compressive, torsional, and bending performances were compared with a standard locked plate. They found that dynamic plates have lower axial stiffness and torsional rigidity than standard locking plates. In addition, it has been reported that the axial stiffness of the dynamic plate is lower than the FCL screw's structure $[4,9]$.

On the other hand, to overcome the long-term stress shielding effect of the metallic fixation plate on bone, a range of alternative composite materials have been tested [10]. To avoid toxic responses to thermoset composites, attention has focused on thermoplastic composites, which lead to good compatibility with fractured bone [11]. In this regard, Tonino et al. [12] studied the mechanical properties of polytrifluormonochlor ethylene (PTFCE) fixation plates, such as failure load, ultimate bending strength, and elastic modulus, using in-vivo test and compared them with standard stainless steel fixation plates. The radiographic images showed a significant reduction in bone mineral density in samples with the stainless-steel fixation plate compared to the PTFCE plate. Gillett et al. [13] developed a thermoplastic internal femoral fixation plate made of nylon 6-10 and polyester (Polybutylene terephthalate; PBT), which was reinforced with $30 \%$ randomly distributed carbon fiber. Due to its similar tensile and flexural strength to bone, they concluded that this plate could prevent stress shielding in the femur. Bagheri et al. [14] developed a new carbon fiber CF/Flax/Epoxy composite plate and assessed its fatigue properties under cyclic axial compression. They compared the new plate with the traditional metallic one and showed stress shielding reduction while the composite plate provided the same stability compared to the metallic plate. Mudrick et al. [15] evaluated a PEEK locking plate's bending strength and compared it with a non-locking 
titanium plate. This represented a new locking fixation, applicable for small bone fractures, which provides adequate overall stiffness compared to the standard fixation plate. Chakladar et al. [16] compared metallic plates to E-glass/epoxy ones using a three-point bending test on ulnar bone specimens. They found the optimal screw position by minimizing the stress shielding and indicated that the composite fixation plates could replace the metallic implants. Yeon et al. [17] developed a Polylactic acid/hydroxylapatite/Silk (PLA/HA/Silk) composite bone clip using three-dimensional (3D) printing technology and investigated cell viability, adhesion, and axial compression strength through in-vivo animal studies. Its excellent mechanical stability and high biocompatibility make this composite a suitable candidate for internal bone fixation systems. Qiao et al. [18] carried out fracture tests on animal femurs with nano-hydroxyapatite/polyamide66/glass fiber (n-HA/PA66/GF) compared to titanium fixation plates. They demonstrated that the n-HA/PA66/GF plate has no adverse effects on muscles or bone, and union callus was better formed around the composite plate in contrast to the titanium plate. Rendenbach et al. [19] studied interfragmentary movements and the fatigue behavior of fixation plates made of Bisphenol a glycidyl methacrylate/Triethylene glycol dimethacrylate (BisGMA/TEGDMA) matrix reinforced by differently-oriented glass fiber under compressive cyclic dynamic load. By comparing this plate with the locking titanium one, they realized that the use of a glass-fiber-reinforced composite plate improved fatigue strength compared to the titanium plate.

This wide range of materials and manufacturing methods offer different possibilities to achieve the desired stiffness of constructed fiber-reinforced implants. The GF/PP composite due to its biocompatibility is known as one of the best materials for an internal bone fixation system and other medical applications $[10,11,20,21]$. Hence, internal fracture fixation plates made of polypropylene and three types of glass fibers were developed in this study. The effects of different manufacturing processes (3D printing and heat-compressing) on the 
mechanical properties of these new fixation plates was investigated through in-vitro biomechanical experiments. The stability, overall stiffness, and failure load of these fixation plate systems were experimentally studied under axial compression loading in stable and unstable bone fractures. Furthermore, the fixation plates' strain fields and the value of failure strain were obtained using the digital image correlation (DIC) technique.

\section{Materials and experimental methods}

\subsection{Composite fixation plates fabrication}

The usage of thermoplastic-based composite implants is increasing dramatically because, compared to thermoset-based implants, they provide more fracture toughness and use less manufacturing time (chemical reaction time) and can be reshaped via heat exposure during surgery [22-24]. Hence, to obtain the appropriate range of mechanical properties, different composite fixation plates using three types of glass fibers in conjunction with polypropylene, as a biocompatible matrix, were constructed in this study. PP/Short Chopped Glass Fiber (PPSCGF), PP/Long Glass Fiber (PPLGF), and PP/Long Glass Fiber Yarn (PPLGFY) composites were used in the fabrication of the fixation plates.

It was reported that the closest screw to the fracture site plays the crucial role in the stiffness of the fixation plate structure, and also more than three screws should be used in order to have sufficient stability in each fractured site [25]. Therefore, the standard model for the tibia middle shaft fixation plate was designed with $110 \mathrm{~mm}$ length, $25 \mathrm{~mm}$ width, and $5.5 \mathrm{~mm}$ thickness (Figure 1-a).

The PP/Short Chopped Glass Fiber granules with the density of $1.04 \mathrm{~g} / \mathrm{cm}^{3}$ and the volume fraction of $15 \%$ and the 20 prepreg layers of unidirectional oriented fiber with the density of $1.27 \mathrm{~g} / \mathrm{cm}^{3}$ and the volume fraction of $30 \%$ were used to manufacture the PPSCGF and PPLGF fixation plates, respectively. These materials were put in a six pins stainless-steel mold. The hot press was then applied to the required pressure and temperature according to a 
predetermined schedule (Figure 1-b). Afterward, the mold was gradually cooled to room temperature. Finally, the compressed composite bone plate was ejected from the mold die.

The PPLGFY composite fixation plate was created using the 3D printing technique, which is widely used in tissue engineering [26]. The fixation plate model was prepared as a G-code file using slic3r V1.3.0 software for 3D printing. It was made by FDM machine with a special nozzle designed for simultaneous feeding of continuous fiber melting (Figure 1-c). The continuous E-glass fiber yarn with $0.1 \mathrm{~g} / \mathrm{m}$ mass per length and $15 \%$ volume fraction was held by a pulley and was guided into the nozzle tip through a specially made orifice on the nozzle side, and the raster of molten PP filament embedded with the fiber yarn was deposited on the previous layer. The nozzle and the bed temperatures were set at $220^{\circ} \mathrm{C}$ and $80^{\circ} \mathrm{C}$, respectively. The inner diameter of the nozzle was $0.4 \mathrm{~mm}$. The thickness of each layer was $0.22 \mathrm{~mm}$. The print speed was configured at $5 \mathrm{~mm} / \mathrm{sec}$ to ensure smooth printing. Figure 1-c indicates that the PP matrix surrounded the arrangement of the parallel fibers.

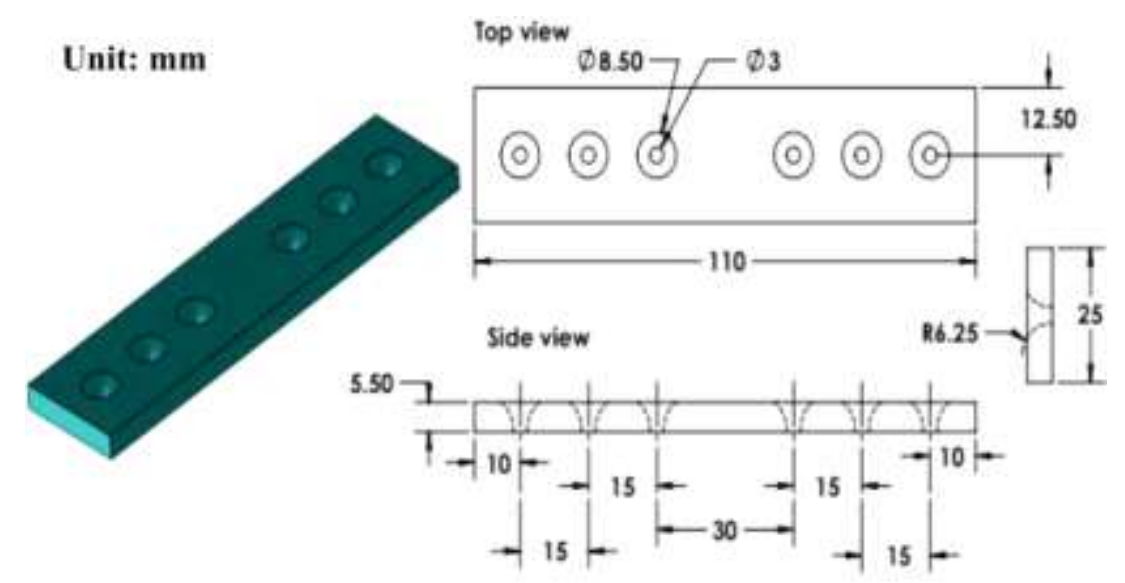

(a)
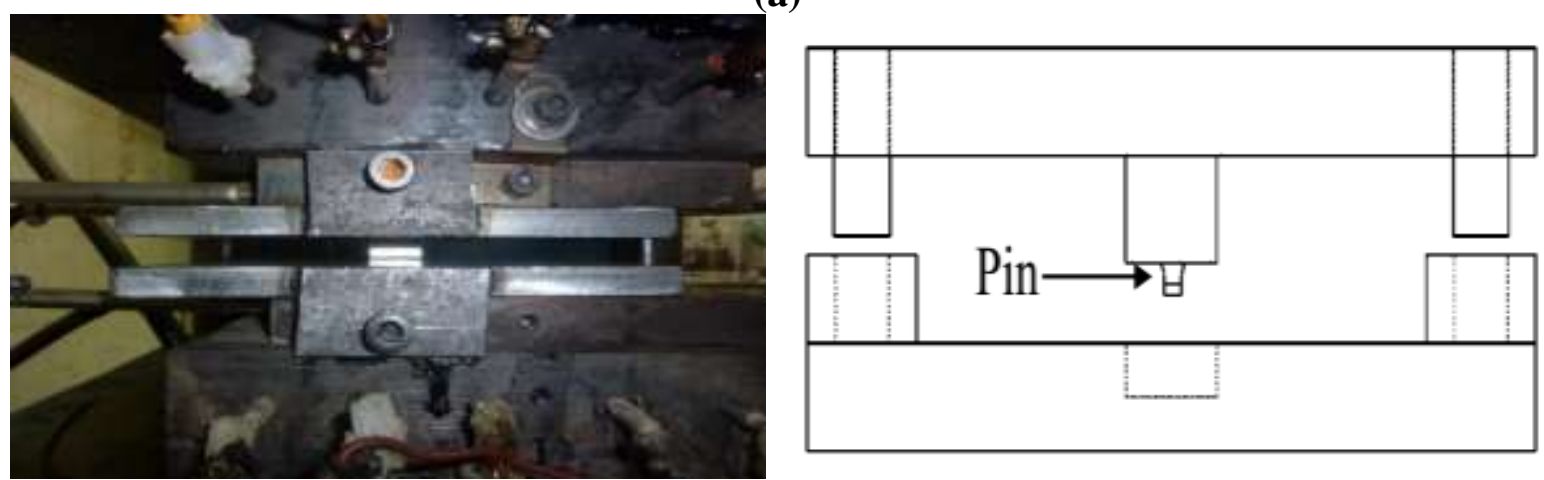

(b) 

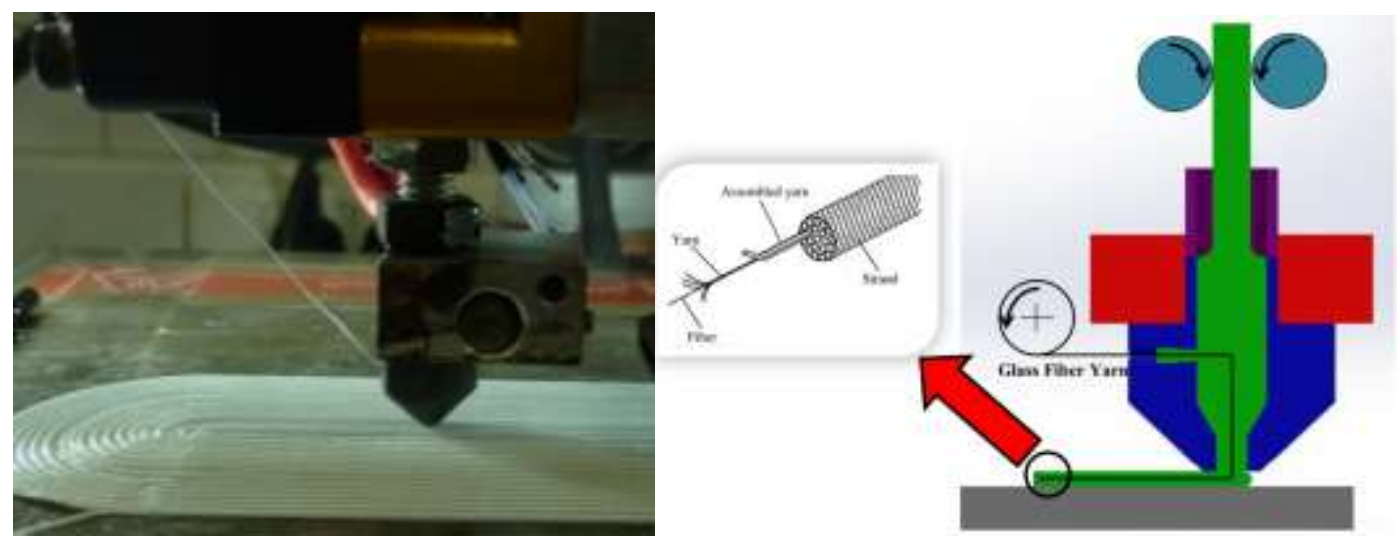

(c)

Figure 1. (a) The specimen geometry of the composite fixation plate (All dimensions in mm), (b) Manufacturing specimens by thermoforming hot press method, and (c) 3D printing technique manufacturing [21].

In both methods, all sharp edges were removed after the completion of the manufacturing process. The fabricated composite fixation plates are shown in figure 2.

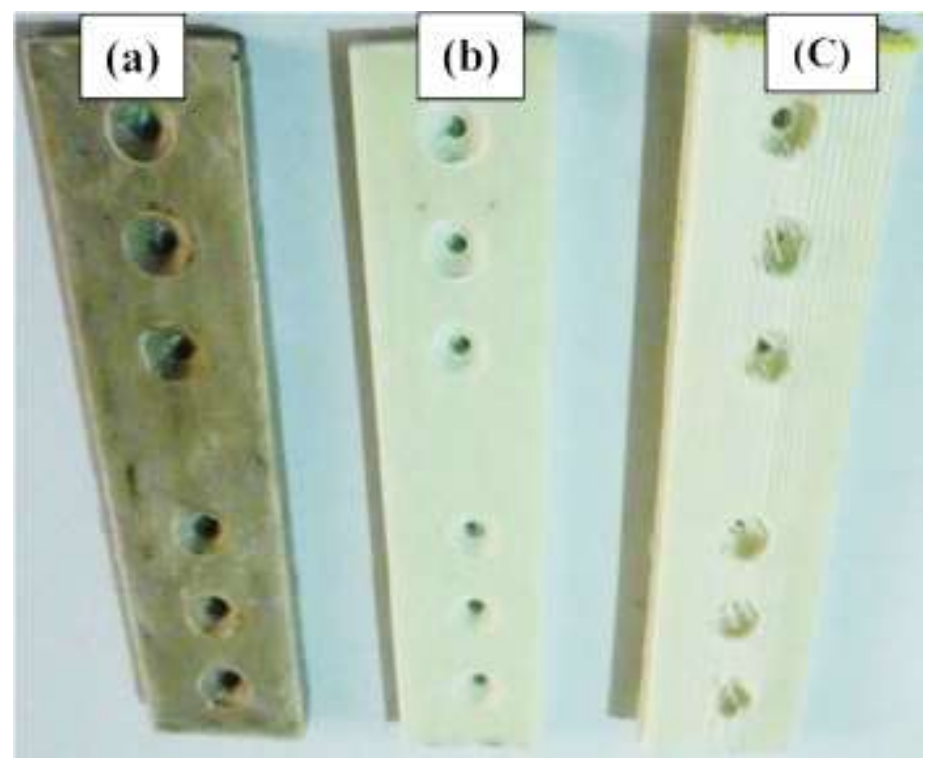

Figure 2. (a) PPSCGF, (b) PPLGF, and (c) PPLGFY fixation plates [21].

\subsection{Mechanical properties tests}

Physical and mechanical properties tests, including density (ASTM D792), tensile (ASTM D3039), compression (ISO844), four-point bending (ASTM D7264), and shear (ASTM D3518) were performed. Therefore, Young's, flexural, and shear modulus and tensile, compressive, flexural, and shear strength of all three types of the GF/PP composite specimens were determined. The test setup is indicated in figure 3. The digital image correlation (DIC) 
technique was employed in the tensile, compression, and shear tests to obtain an accurate strain field. Also, to evaluate the effect of glass fibers on these composites properties, properties of neat PP specimens were characterized through the aforementioned tests.

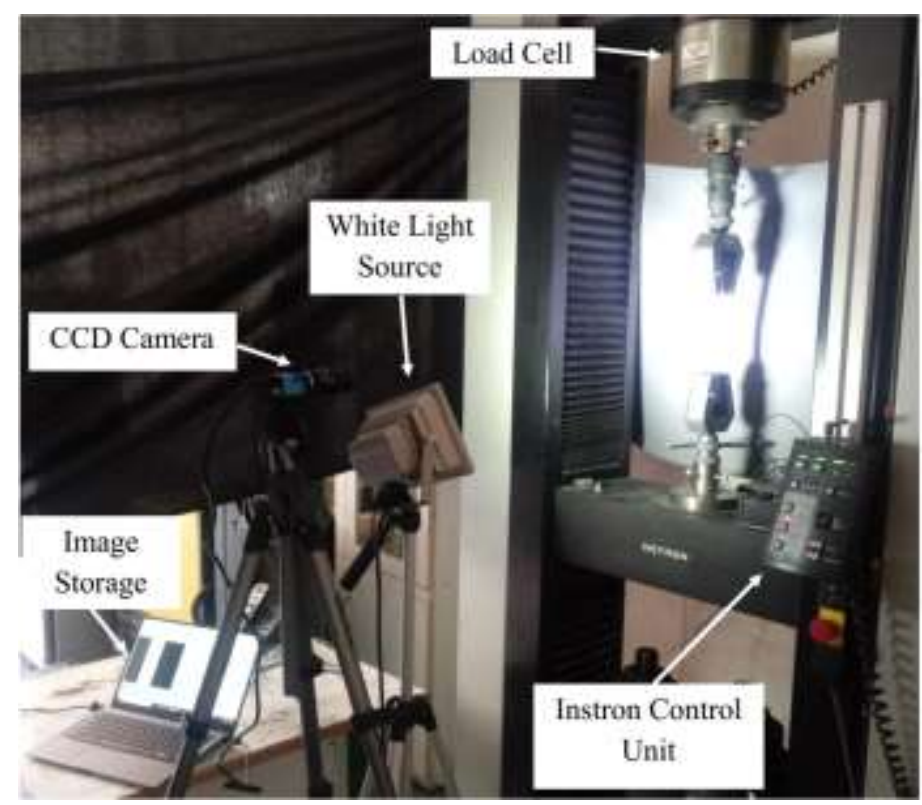

(a)

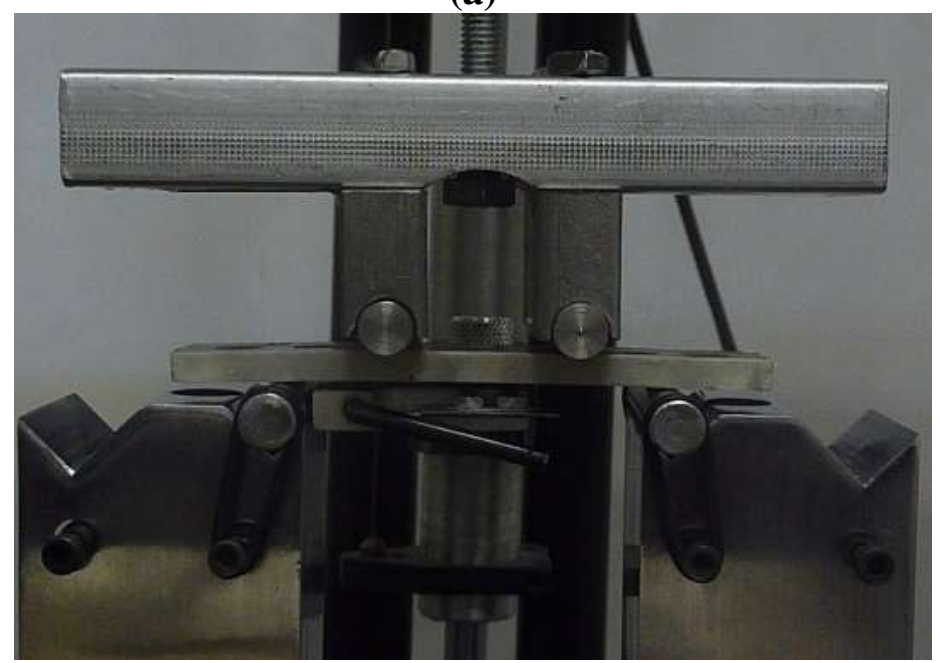

(b)

Figure 3. The setup of the (a) tensile, compression and shear tests, and (b) four-point bending test [21].

\subsection{In-vitro experimental analysis}

\subsubsection{Specimens preparation}

The animal bones have advantages such as low cost, easier storage, and availability over human cadaver specimens [27]. Since the bovine tibia bone geometry and mechanical properties are similar to the human one, it is the best choice for research usage [27]. The fresh 
bovine tibia bones were obtained from a local butcher shop immediately after slaughter, and the surrounding soft tissues were removed. To prepare fractured bone specimens, the specimens were cut in half with a saw. The fixation plate structures were considered in $1 \mathrm{~mm}$ (stable fracture) and $10 \mathrm{~mm}$ (unstable fracture) gaps to simulate comminuted fracture patterns [28]. A gap of $10 \mathrm{~mm}$ was assumed to simulate the worst-case scenario. Then, the bones were drilled to insert six 3-mm metallic cortical screws. Aligning, drilling, and placing the screws were conducted based on the corresponding standards [27].

To increase the bone blood circulation beneath the plate and decrease the axial stiffness of the fixation plate structure, the use of non-contact plates is common. It is recommended to maintain mechanical stability, the distance between the fixation plate and bone periosteal surface should not exceed $2 \mathrm{~mm}$ [3]. Therefore, fixation plate systems with a distance of 2 $\mathrm{mm}$ from the bone were mounted on both stable and unstable fractured bones using an automatic screwdriver (Figures 4-a and 4-b). Finally, the proximal and distal ends of the fixation plate structure were fully fixed using Poly methyl methacrylate (PMMA) cement and grub screws in a designed fixture, and the fixation plate structure was mounted on a testing machine (Figure 4-c).

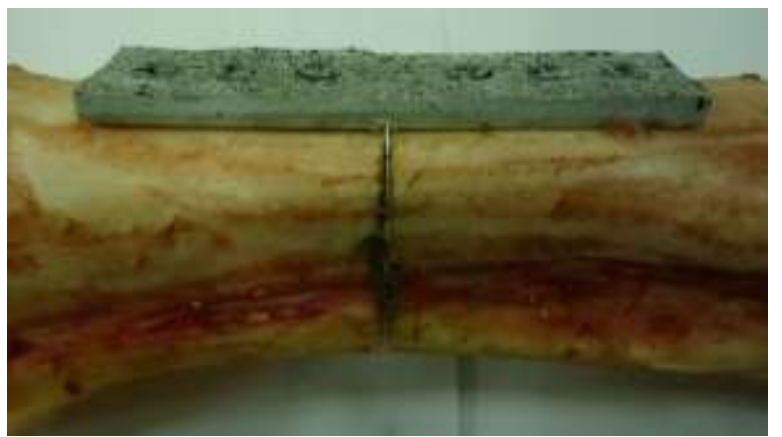

(a)

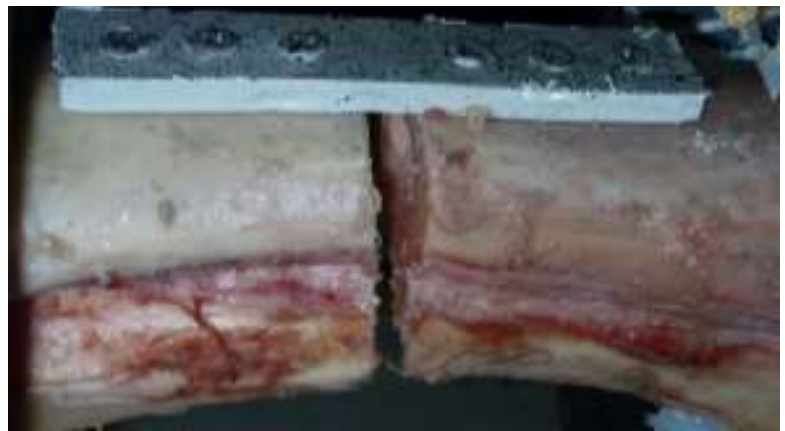

(b) 


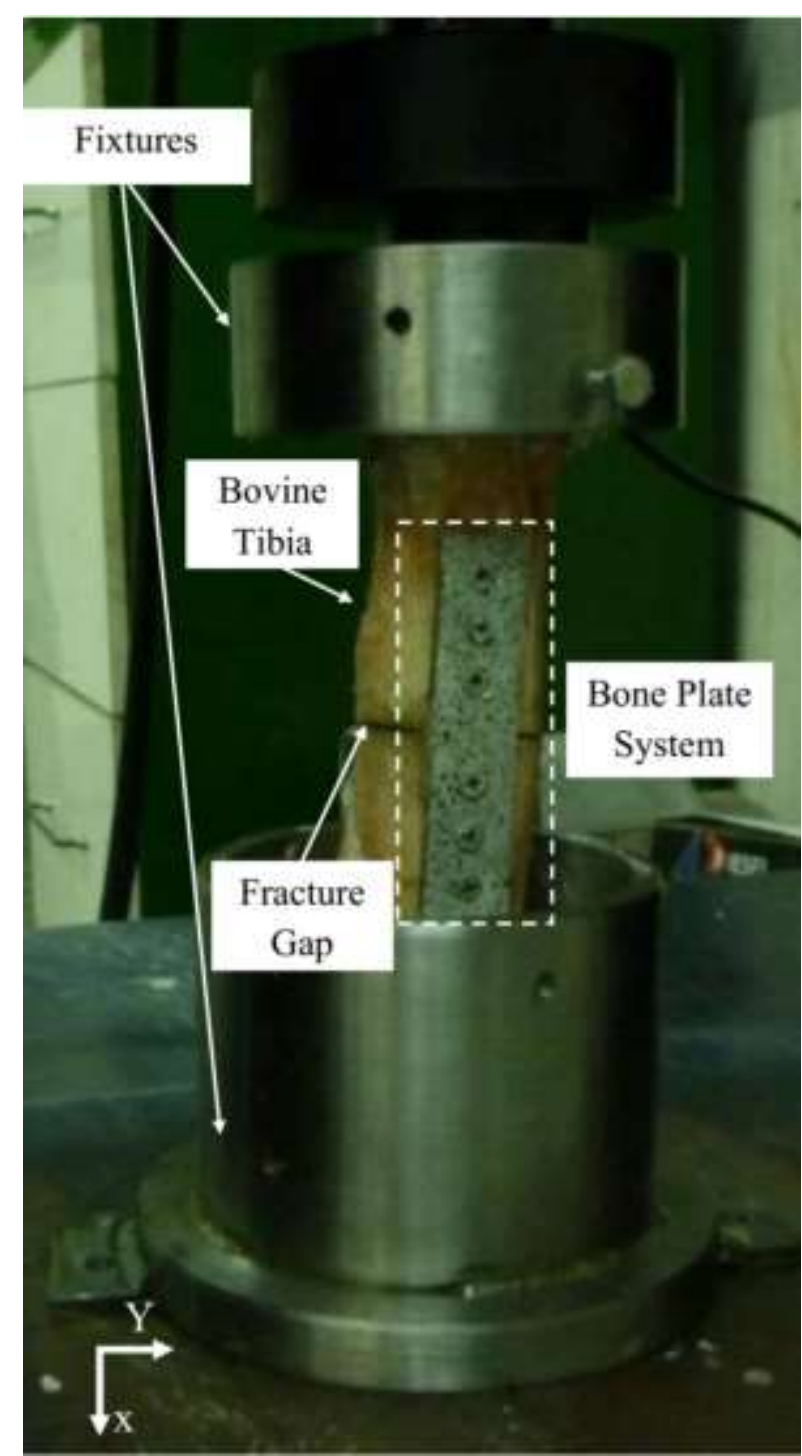

(c)

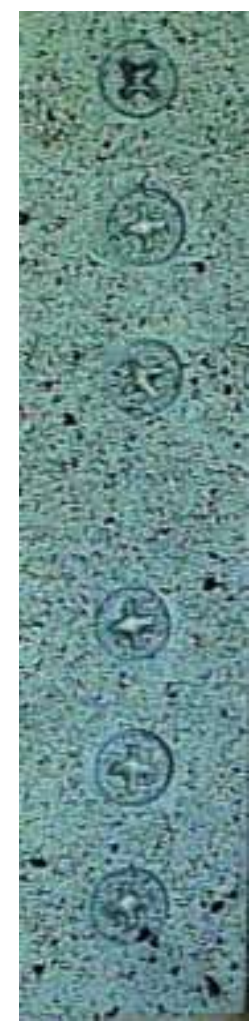

(d)

Figure 4. The types of bone fracture; (a) stable (1 mm gap), and (b) unstable (10 mm gap) [28]. (c) The sample prepared for axial compression test, and (d) the speckle pattern used in the DIC technique.

\subsubsection{Measurement systems}

To assess the deformation and strain field of the fixation plates, the $2 \mathrm{D}$ digital image correlation (DIC) technique was used. For this purpose, fixation plates were sprayed with a speckle pattern according to standard protocols [29] (Figure 4-d).

The image analysis system captured many digital images using a charge-coupled device (CCD) camera with $1 \mathrm{fps}$ speed, which were stored in a camera-connected computer. A method called fringe projection was used to reduce the effects of off-plane displacement 
during bending loads [30]. Eventually, the deformation and strain field of the fixation plates were calculated using GOM software.

Furthermore, the stiffness, failure load, and displacement values were calculated directly from the obtained load-displacement curve using a compression machine (WDW-300E with $60 \mathrm{kN}$ load cell).

In both measurement systems, conditioning and calibrating procedures were conducted according to manufacturer recommendations $[27,29]$.

\subsubsection{Axial compression test}

The tibia loading condition during various daily activities such as standing, walking, running, and climbing stairs are axial compression. In this research, fixation plate structures were tested under simulated physiological loading conditions based on anatomic single-legged stance phase of walking. Therefore, to determine overall stiffness, failure load and modes, and the strain field of fixation plate systems, an axial compression test was conducted on fixation plate structures. The distal cylindrical pot was fixed in all directions while the compressive force was applied with a speed of $2 \mathrm{~mm} / \mathrm{sec}$, and force was continued until failure of structure occurred (Figure 5). The validity of the obtained results was checked by repeating each test by using five specimens.

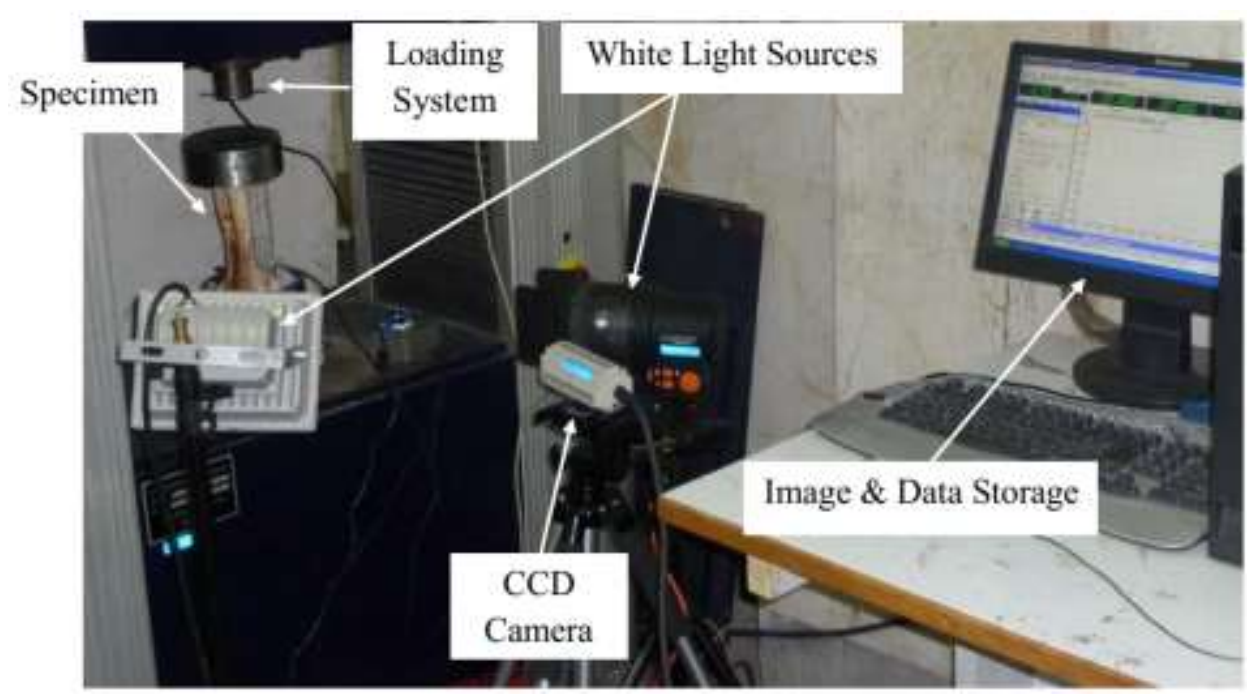

Figure 5. Axial compression test setup. 
The effects of different factors such as muscle forces and knee joint movement were not considered in this study, even though they could increase bone fixation's load-bearing capability and decrease strains of the fixation plate. Furthermore, through such in-vitro biomechanical tests on bovine bone, the effect of the bone surrounding soft tissues cannot be investigated according to clinical conditions.

\section{Results and discussion}

\subsection{Mechanical characterization}

The values of density $(\rho)$, elastic modulus $\left(E_{1}, E_{2}, E_{3}\right)$, tensile $\left(\sigma_{U 1}^{T}, \sigma_{U 2}^{T}, \sigma_{U 3}^{T}\right)$ and compressive $\left(\sigma_{U 1}^{C}, \sigma_{U 2}^{C}, \sigma_{U 3}^{C}\right)$ strength, shear modulus $\left(G_{12}, G_{13}, G_{23}\right)$ and strength $\left(\tau_{12}, \tau_{13}, \tau_{23}\right)$, Poisson's ratio $\left(v_{12}, v_{13}, v_{23}\right)$, flexural modulus $\left(E_{B}\right)$ and strength $\left(\sigma_{U}^{B}\right)$ of the tested samples are shown in Table 1.

Table 1. The mechanical properties of proposed bone plates [21].

\begin{tabular}{|c|c|c|c|c|}
\hline Properties & PPSCGF & PPLGF & PPLGFY & Neat PP \\
\hline$\rho\left(\mathrm{kg} / \mathrm{m}^{3}\right)$ & $1040 \pm 10$ & $1270 \pm 10$ & $490 \pm 10$ & $946 \pm 5$ \\
\hline$E_{1}(G P a)$ & \multirow{3}{*}{$2.35 \pm 0.15$} & $20.10 \pm 2.00$ & $7.87 \pm 0.50$ & \multirow{3}{*}{$0.77 \pm 0.10$} \\
\hline$E_{2}(G P a)$ & & $4.20 \pm 0.30$ & $1.00 \pm 0.20$ & \\
\hline$E_{3}(G P a)$ & & $4.20 \pm 0.30$ & $1.00 \pm 0.20$ & \\
\hline$\sigma_{U 1}^{T}(M P a)$ & \multirow{3}{*}{$30 \pm 5$} & $400 \pm 30$ & $150 \pm 20$ & \multirow{3}{*}{$20 \pm 5$} \\
\hline$\sigma_{U 2}^{T}(M P a)$ & & $20 \pm 2$ & $10 \pm 1$ & \\
\hline$\sigma_{U 3}^{T}(M P a)$ & & $20 \pm 2$ & $10 \pm 1$ & \\
\hline$\sigma_{U 1}^{C}(M P a)$ & \multirow{3}{*}{$45 \pm 5$} & $70 \pm 5$ & $20 \pm 5$ & \multirow{3}{*}{$30 \pm 5$} \\
\hline$\sigma_{U 2}^{C}(M P a)$ & & $50 \pm 5$ & $15 \pm 5$ & \\
\hline$\sigma_{U 3}^{C}(M P a)$ & & $50 \pm 5$ & $15 \pm 5$ & \\
\hline$G_{12}(G P a)$ & \multirow{3}{*}{$0.80 \pm 0.10$} & $1.42 \pm 0.20$ & $1.15 \pm 0.20$ & \multirow{3}{*}{$0.25 \pm 0.1$} \\
\hline$G_{13}(G P a)$ & & $1.33 \pm 0.20$ & $1.10 \pm 0.20$ & \\
\hline$G_{23}(G P a)$ & & $1.33 \pm 0.20$ & $1.10 \pm 0.20$ & \\
\hline$\tau_{12}(M P a)$ & \multirow{3}{*}{$20 \pm 5$} & $40 \pm 2$ & $20 \pm 2$ & \multirow{3}{*}{$10 \pm 5$} \\
\hline$\tau_{13}(M P a)$ & & $30 \pm 2$ & $10 \pm 2$ & \\
\hline$\tau_{23}(M P a)$ & & $30 \pm 2$ & $10 \pm 2$ & \\
\hline$v_{12}$ & $0.35 \pm 0.05$ & $0.15 \pm 0.05$ & $0.25 \pm 0.05$ & $0.45 \pm 0.05$ \\
\hline
\end{tabular}




\begin{tabular}{|c|c|c|c|c|}
\hline$v_{13}$ & & $0.10 \pm 0.05$ & $0.15 \pm 0.05$ & \multirow{2}{*}{} \\
\cline { 1 - 3 }$v_{23}$ & & $0.10 \pm 0.05$ & $0.15 \pm 0.05$ & \\
\hline$E_{B}(G P a)$ & $2.10 \pm 0.20$ & $16.20 \pm 0.20$ & $2.30 \pm 0.20$ & $0.9 \pm 0.2$ \\
\hline$\sigma_{U}^{B}(M P a)$ & $27 \pm 5$ & $185 \pm 5$ & $44 \pm 5$ & $35 \pm 5$ \\
\hline
\end{tabular}

Since fixation plate's elastic modulus plays a vital role in the healing of fractured bone [10], one of the aims of fabricating composite specimens with different fiber types and volume fractions was to achieve a specific longitudinal elastic modulus range. A comparative graph of the axial Young's modulus of manufactured fixation plates is shown in figure 6 , and it demonstrates that the fixation plates' Young's modulus at three different levels are less than Young's modulus of bone. The strength and modulus values of produced composite plates were 30-400 MPa and 2.35-20.10 GPa, respectively, which are in the range of cortical bone values (50-150 MPa, 7-30 GPa [31]). The flexural stiffness, modulus, and strength of the composite fixation plates were 0.44-3.27 N.m/ ${ }^{\circ}$ 2.10-16.20 GPa, and 27-185 $\mathrm{MPa}$, respectively. Furthermore, these composite fixation plates offer $90 \%$ weight reduction compared to the metallic ones. Based on characteristic evaluation, the PPLGF composite fixation plate has superior mechanical properties compared to the PPLGFY and PPSCGF plates.

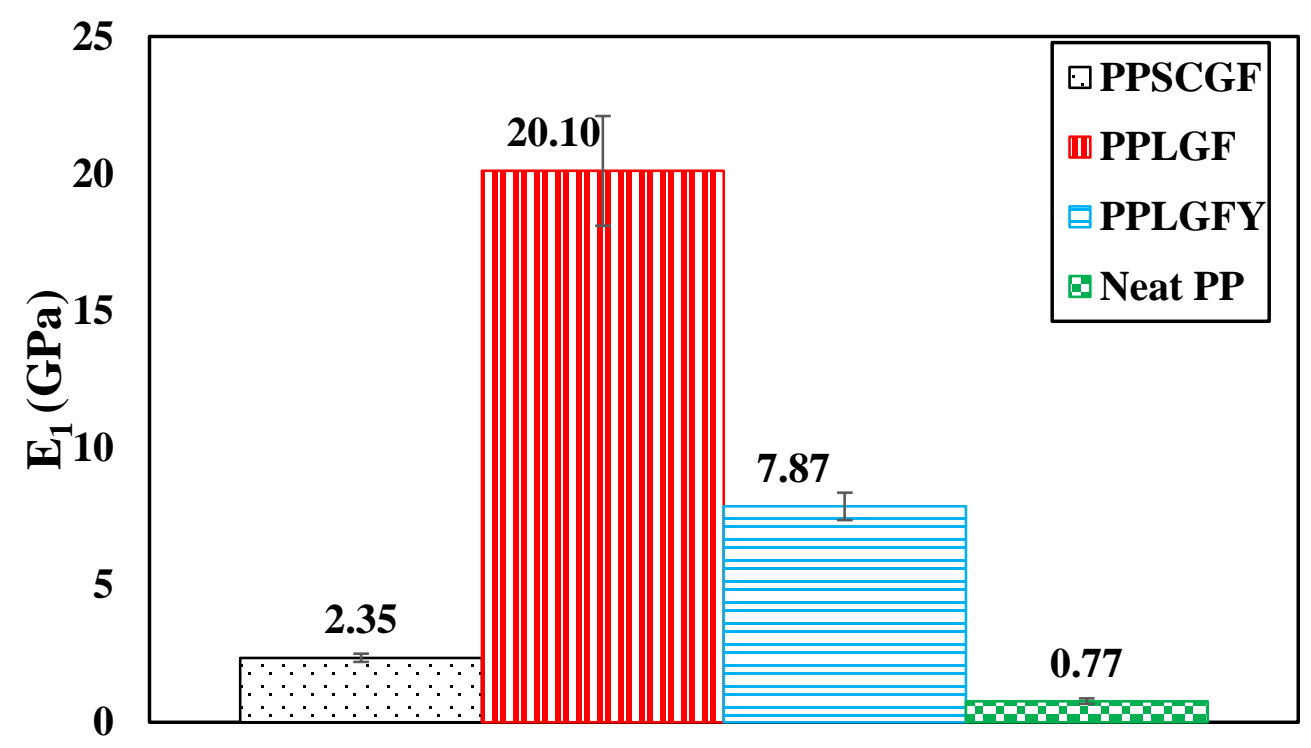

Figure 6. The comparison of the fixation plates Young's modulus through the fiber direction $(\mathrm{p}<0.01)[21]$. 
Since the GF/PP bone plates have adequate bending modules with lower Young's modulus, they would provide similar mechanical fixation yet lower stress shielding than the standard metallic plate.

The results of previous studies on the mechanical properties of reinforced composites used as flexible orthopedic fixation to facilitate the replacement of traditional metallic plates were summarized and compared with the obtained results in the current study (Table 2). There are some differences between the results of the current study and the literature due to different fiber and matrix constituent, fiber orientation, dissimilar fiber or matrix volume fraction and various manufacturing methods. However, the presented mechanical properties of the proposed GF/PP composites were within the reported range in previous studies.

Table 2. The comparison of mechanical properties of the current GF/PP composites to previous studies.

\begin{tabular}{|c|c|c|c|c|c|}
\hline Composite & $E_{1}(\mathrm{GPa})$ & $E_{B}(\mathrm{GPa})$ & $\sigma_{U 1}^{T}(\mathrm{MPa})$ & $\sigma_{U}^{B}(\mathrm{MPa})$ & References \\
\hline PPSCGF & 2.35 & 2.10 & 30 & 27 & Present study \\
\hline PPLGF & 20.10 & 16.20 & 400 & 185 & Present study \\
\hline PPLGFY & 7.87 & 2.30 & 150 & 44 & Present study \\
\hline Neat PP & 0.77 & 0.90 & 20 & 35 & Present study \\
\hline Carbon/Flax/Epoxy & 41.70 & 57.40 & 399.80 & 510.60 & {$[14]$} \\
\hline PP/Glass (Twintex) & $7.50-19$ & - & $215-550$ & $220-250$ & {$[20]$} \\
\hline Kenaf / PLA & - & $3-14$ & - & $40-100$ & {$[31]$} \\
\hline Hap/ PLLA & $2.50-4.20$ & - & $10-70$ & - & {$[32]$} \\
\hline MAWs/PLA & - & - & $46-108$ & $88-190$ & {$[33]$} \\
\hline Bioglass/ PCL & - & $8-18$ & - & $120-200$ & {$[34]$} \\
\hline $\begin{array}{c}\text { PG/ methacrylate-modified } \\
\text { oligolactide }\end{array}$ & $15-20$ & $15-20$ & $80-220$ & $100-200$ & {$[35]$} \\
\hline PG/PLA & - & $5-12$ & - & $50-120$ & {$[36]$} \\
\hline Flax/Epoxy & $12.98-30.00$ & - & $\begin{array}{l}148.10- \\
200.00\end{array}$ & - & {$[37-39]$} \\
\hline $\begin{array}{c}\text { Glass/Flax/Epoxy } \\
\text { CF/Flax/Epoxy }\end{array}$ & $16.51-31.97$ & $30.03-39.84$ & $\begin{array}{c}301.87- \\
408.25\end{array}$ & $\begin{array}{c}499.98- \\
591.25\end{array}$ & {$[40]$} \\
\hline $5.09-6.48$ & $14.41-23.84$ & $\begin{array}{l}172.40- \\
288.30\end{array}$ & $\begin{array}{c}85.00- \\
160.42\end{array}$ & {$[41]$} \\
\hline
\end{tabular}




\begin{tabular}{|c|c|c|c|c|c|}
\hline Sisal/CF/Polyester & $1.99-2.78$ & $6.52-11.33$ & $\begin{array}{c}84.44- \\
107.51\end{array}$ & $\begin{array}{c}140.89- \\
169.14\end{array}$ & [42] \\
\hline $\begin{array}{c}\text { Glass/BisGMA/TEGDMA } \\
\text { Resin (UF-BG) }\end{array}$ & - & 17.00 & - & 802.00 & [43] \\
\hline $\begin{array}{c}\text { Glass/BisGMA/TEGDMA } \\
\text { Resin (UFS-BG) }\end{array}$ & - & 15.30 & - & 602.00 & \\
\hline
\end{tabular}

\subsection{Axial compression test results}

\subsubsection{Load-displacement curves of the fixation plate structures}

The fracture site length is the most critical factor to change the axial, flexural, and torsional stiffness and strength. Hence, the effects of fracture site length and the change of fixation plate's material properties on the biomechanical behavior of the fixation plate structure were investigated in this study. Figures 7-a and 7-b illustrate these two factors' effect on the loaddisplacement curves of the fixation plate structures.

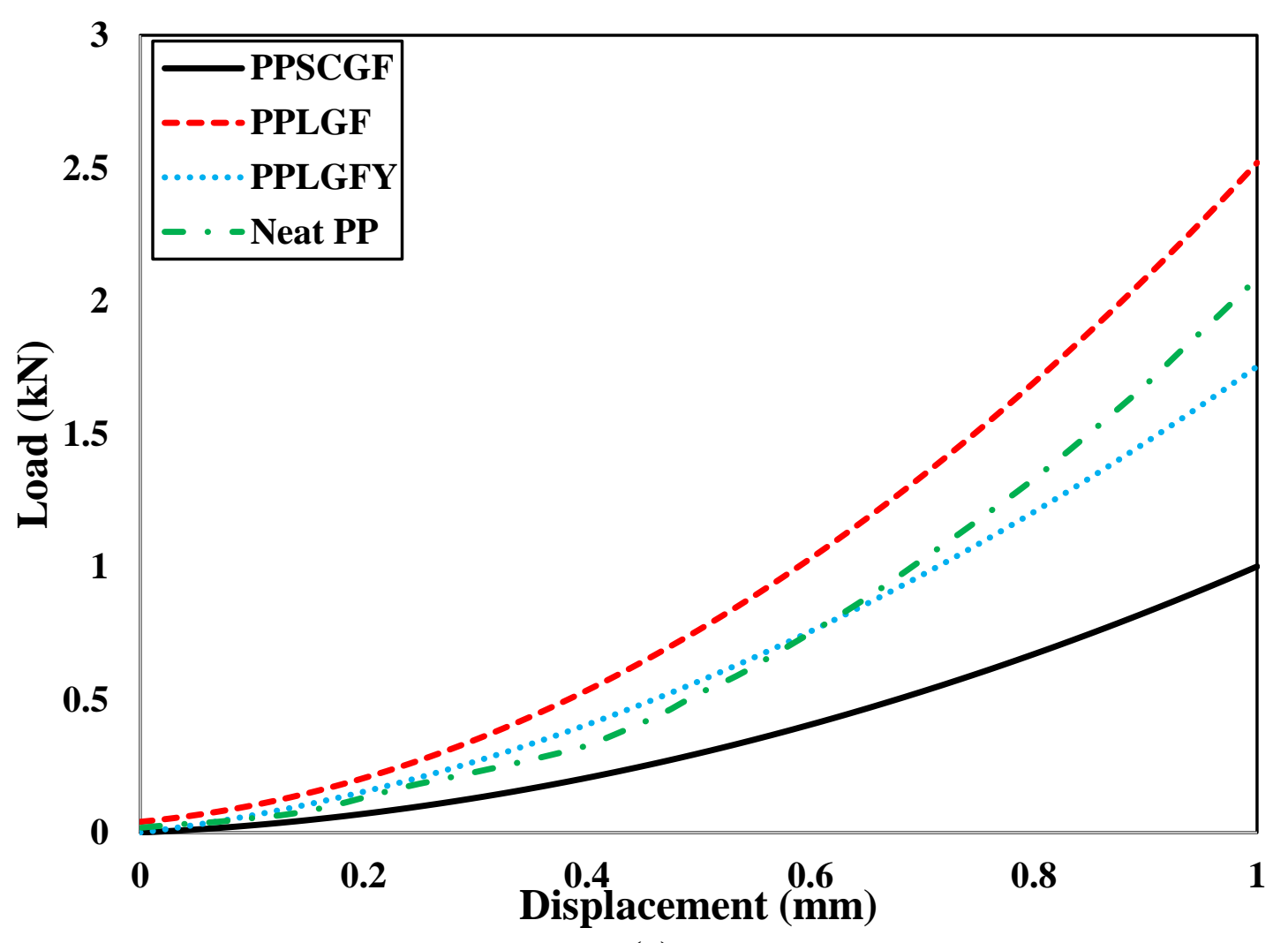

(a) 


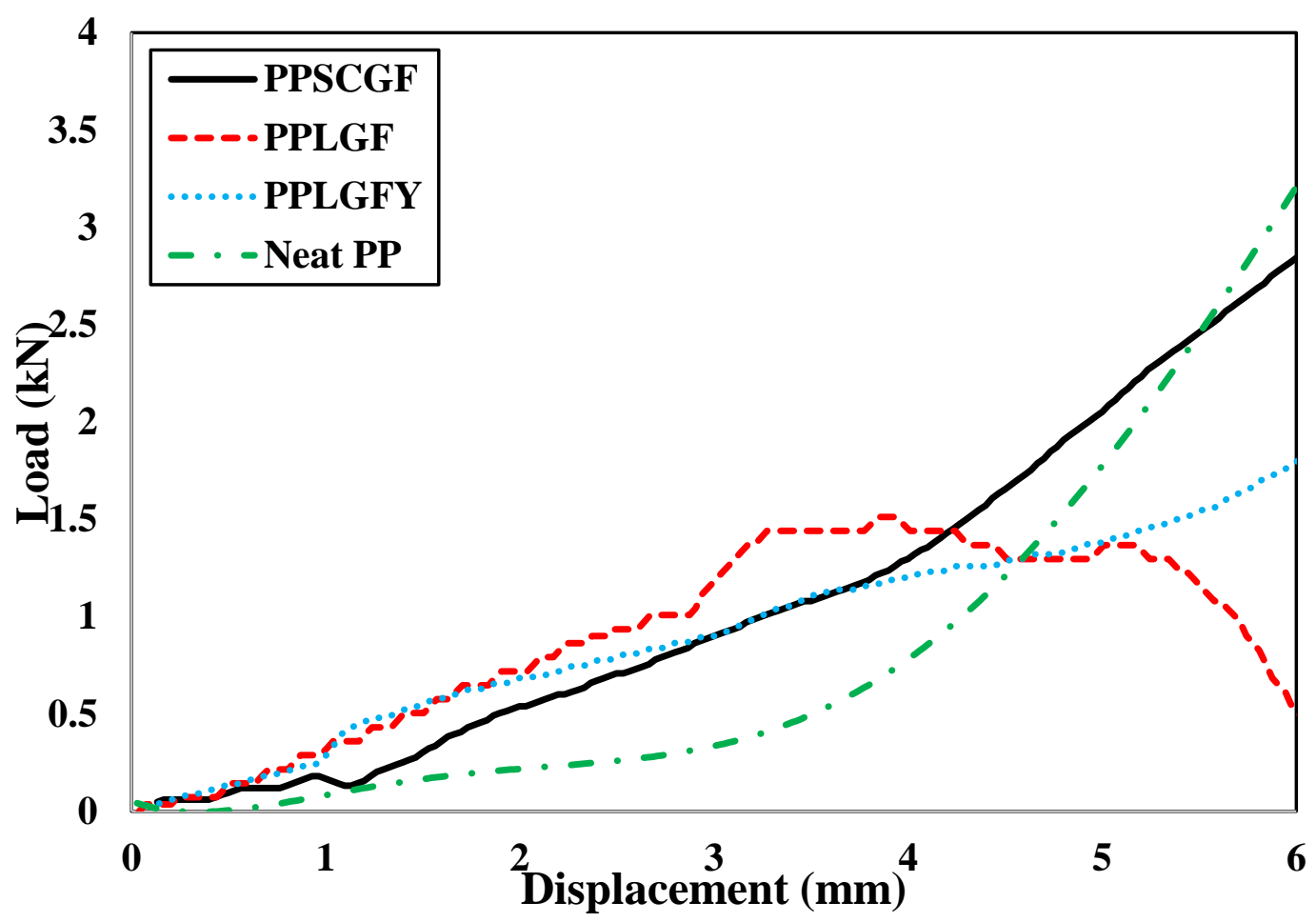

(b)

Figure 7. Load-displacement curves of the fixation plate structures for (a) stable and (b) unstable bone fractures.

As shown in figure 7-a, the PPLGF fixation plate exhibits greater load-bearing capacity than the others. Both long fiber composites (PPLGF and PPLGFY) have better properties compared to the PPSCGF. Short chopped fibers were not as efficient as long continuous fibers since chopped fibers have a random orientation and a lower ratio of fiber length to carry full axial loads. Furthermore, the neat PP has undergone densification and behavior change due to complete plastic behavior. In general, the neat PP plate does not necessarily have appropriate properties for clinical usage.

The load-displacement curves of the unstable fracture for different fixation plate structures are illustrated in figure 7-b. Before the creation of the first matrix crack, the behavior of fixation plate structure was linear. Due to the plastic deformation or breakage of the fixation plate, different behavior in the structures and sudden fall in their curves were observed. Due to the early onset of cracks around the screw holes and the propagation of matrix cracking, early failures occurred in the PPLGF fixation plate, which reduce the system ultimate loadbearing capacity. In contrast, the PPLGF fixation plate has the maximum flexural modulus 
and strength. However, there are some limitations in choosing such layered composites. In other words, they do not have sufficient strength in the transverse direction of the fibers; moreover, the compressive loading increases the shear stress in the vicinity of the screw holes. The low interlayer and interfacial properties of these composites quickly cause crack growth along the fibers.

Due to matrix cracking and fibers breakage along the compression surfaces, primary failure occurred in all specimens, and then crack growth permeated underneath the screw holes, but due to the plastic flexural behavior, the PPSCGF and PPLGFY fixation plates tolerated the compressive loading. However, the presence of the fractures beneath the screw holes in these plates has impaired their function.

\subsubsection{Overall stiffness of the fixation plate structures}

The ideal fixation plate must have sufficient rigidity to allow the callus zone primary creation in the healing bone process. The fixation rigidity is the function of several factors such as the materials of plate and screws, screws number, size, and position, sufficient plate length in the fracture site, and the distance between the plate and bone. The overall stiffness was recorded for all specimens under axial compressive loading. Figure 8 shows the comparative diagram of the fixation plate structures overall stiffness in the stable and unstable fracture. The overall stiffness of the structures was calculated as the slope of the linear portion of the loaddisplacement curves. 


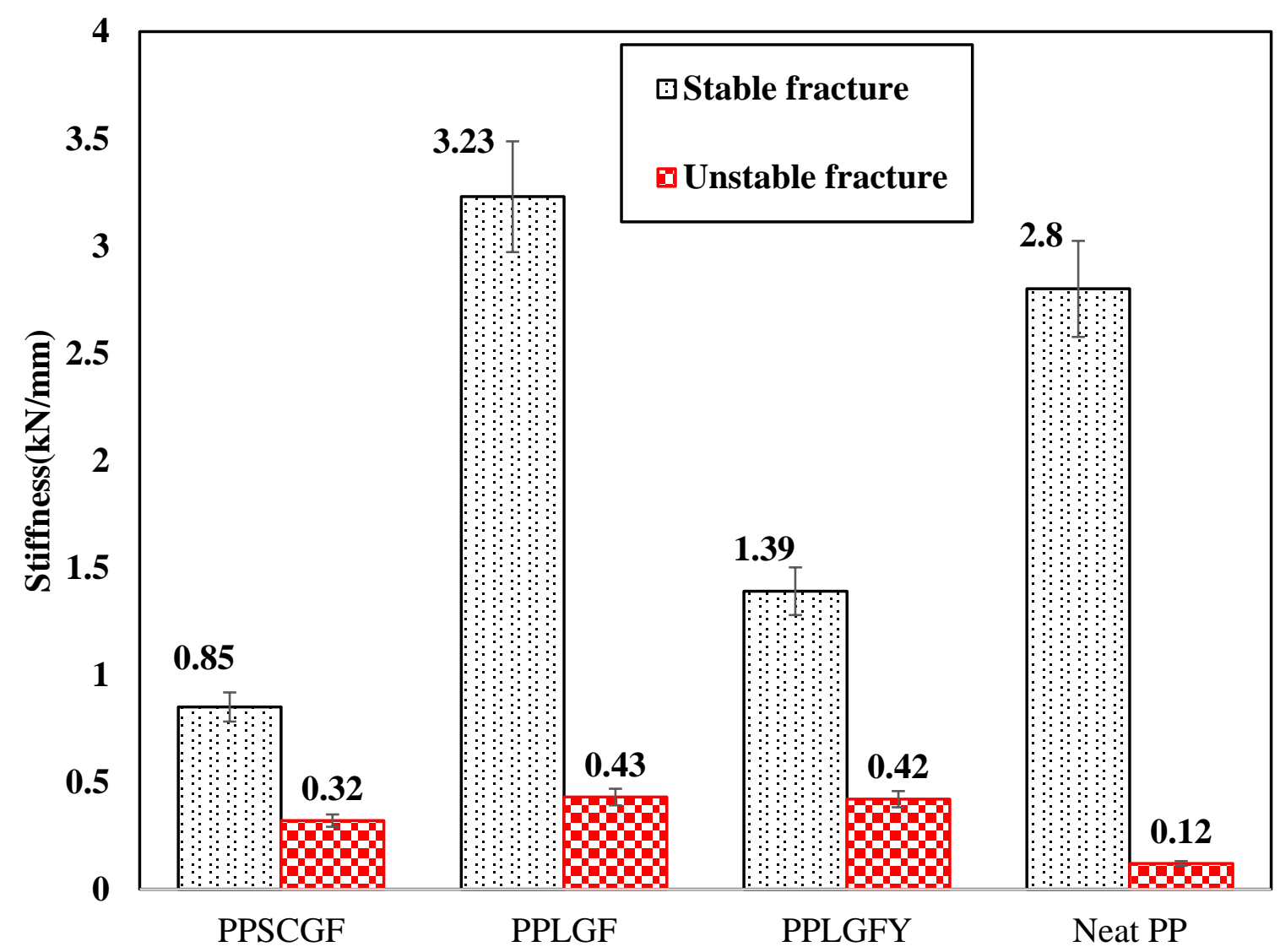

Figure 8. The comparison of the fixation plate structures stiffness in the stable and unstable bone fractures $(\mathrm{p}<0.01)$.

In the stable bone fracture, the stiffness of the PPLGF, PPLGFY, and PPSCGF fixation plate structures were $3.23 \pm 0.10 \mathrm{kN} / \mathrm{mm}, 1.39 \pm 0.10 \mathrm{kN} / \mathrm{mm}$, and $0.85 \pm 0.10 \mathrm{kN} / \mathrm{mm}$, respectively. The stiffness of the PPLGFY and PPSCGF were 57\% and 74\% lower than PPLGF in the stable bone fracture; however, no significant difference was found between the stiffness of the fixation plate structures in the unstable bone fracture. The usage of alternative fixation methods such as parallel plate construction or screw position change might be better options for unstable bone fracture. Generally, the axial stiffness of GF/PP fixations for both stable and unstable bone fracture is within the reported range in previous studies of metallic $[4,6,8,45-47]$ and composite $[14,44]$ fixation plate. The comparable axial stiffness of the fractured bone with metallic and composite plates can be seen in Table 3. 
Table 3. The comparison of stiffness of the current GF/PP plates to previous studies.

\begin{tabular}{|c|c|c|c|c|}
\hline Sample & Method & Bone fracture type & Stiffness $(\mathrm{kN} / \mathrm{mm})$ & References \\
\hline \multirow{2}{*}{$\begin{array}{c}\text { Far Cortical } \\
\text { Non-locking } \\
\text { PPSCGF plate }\end{array}$} & \multirow[b]{2}{*}{ Experimental } & Stable & 0.85 & \multirow[b]{2}{*}{ Present study } \\
\hline & & Unstable & 0.32 & \\
\hline \multirow{2}{*}{$\begin{array}{l}\text { Far Cortical } \\
\text { Non-locking } \\
\text { PPLGF plate }\end{array}$} & \multirow[b]{2}{*}{ Experimental } & Stable & 3.23 & \multirow[b]{2}{*}{ Present study } \\
\hline & & Unstable & 0.43 & \\
\hline \multirow{2}{*}{$\begin{array}{c}\text { Far Cortical } \\
\text { Non-locking } \\
\text { PPLGFY plate }\end{array}$} & \multirow{2}{*}{ Experimental } & Stable & 1.39 & \multirow[b]{2}{*}{ Present study } \\
\hline & & Unstable & 0.42 & \\
\hline \multirow{2}{*}{$\begin{array}{c}\text { Far Cortical } \\
\text { Non-locking } \\
\text { Neat PP plate }\end{array}$} & \multirow{2}{*}{ Experimental } & Stable & 2.80 & \multirow{2}{*}{ Present study } \\
\hline & & Unstable & 0.12 & \\
\hline $\begin{array}{c}\text { Far Cortical } \\
\text { Locking } \\
\text { Stainless steel } \\
\text { plate }\end{array}$ & \multirow{2}{*}{ Experimental } & \multirow{2}{*}{ Unstable } & 0.36 & \multirow{2}{*}[4]{} \\
\hline $\begin{array}{c}\text { Locking } \\
\text { Stainless steel } \\
\text { plate }\end{array}$ & & & 2.90 & \\
\hline \multirow{2}{*}{$\begin{array}{c}\text { Far Cortical } \\
\text { Locking } \\
\text { Stainless steel } \\
\text { plate }\end{array}$} & \multirow[b]{2}{*}{ Experimental } & Stable & 0.63 & \multirow[b]{2}{*}[6]{} \\
\hline & & Unstable & 0.44 & \\
\hline $\begin{array}{l}\text { Non-locking } \\
\text { CF/Flax/Epoxy } \\
\text { plate }\end{array}$ & \multirow{2}{*}{ Experimental } & \multirow{2}{*}{ Unstable } & 0.64 & \multirow{2}{*}{ [14] } \\
\hline $\begin{array}{c}\text { Locking } \\
\text { Stainless steel } \\
\text { plate }\end{array}$ & & & 0.65 & \\
\hline $\begin{array}{c}\text { Non-locking } \\
\text { CF/Epoxy plate }\end{array}$ & \multirow[b]{2}{*}{ Experimental } & \multirow[b]{2}{*}{ Unstable } & 0.62 & \multirow[b]{2}{*}{ [44] } \\
\hline $\begin{array}{l}\text { Non-locking } \\
\text { Stainless steel } \\
\text { plate }\end{array}$ & & & 0.69 & \\
\hline $\begin{array}{c}\text { Locking } \\
\text { Stainless steel } \\
\text { plate }\end{array}$ & Experimental & Unstable & 0.70 & {$[45]$} \\
\hline $\begin{array}{l}\text { Non-locking } \\
\text { Stainless steel } \\
\text { plate }\end{array}$ & FEA & Unstable & $0.60-1.35$ & [46] \\
\hline $\begin{array}{c}\text { Non-locking } \\
\text { Stainless steel } \\
\text { plate }\end{array}$ & FEA & Unstable & 0.97 & {$[47]$} \\
\hline
\end{tabular}


As shown in figure 8, the PPLGF fixation plate structure has the highest axial stiffness in both types of bone fractures. The decrease of the fixation plate mechanical properties reduces the overall stiffness of the fracture fixation structure; consequently, increases the plate bending at unstable bone fracture. In other words, the most important mechanical parameters of fixation plate structure are the axial and flexural properties. The proper elastic modulus combined with the high strength of the PPLGF makes it perfect for internal fracture fixation. However, PPSCGF has lower flexural stiffness, modulus, and strength compared to the other composite plates. Generally, based on the Table 1, the highest obtained flexural modulus is still less than cortical bone flexural modulus (12-17 GPa [48]). This means that these plates can provide perfect behavior in bending compared to metallic fixations and they have provided optimal compressive stiffness during the initial healing phase to stabilize the fracture zone concurrently. Also, they create about 2 to $10 \%$ interfragmentary strain in the secondary healing phase at the callus zone, which can enhance the healing process. Hence, according to stress shielding reduction and required micro-motion provision for the callus formation, the PPLGF and PPLGFY are good candidates for fracture fixation plates. Furthermore, they can provide adequate initial fixation immediately after surgery, and they are capable of absorbing high energy and vibration between the plate and fractured bone when the patient is walking.

\subsubsection{Strain field contours of the fixation plate systems}

Figures 9 and 10 show equivalent von Mises strain contours of fixation plate systems in stable and unstable fracture conditions during loading at different structure displacement stages, respectively. Strain analysis was carried out for all three composite fixation plate structures, and it was concluded that in both fracture conditions the highest strain concentrations of all composite plates happened around screw holes close to the fracture gap and in the plate's middle span above of the fracture site. However, each composite plate 
reacted differently, and the maximum strain occurred at different locations for each one. The strain contours of the two nearest screw holes to the fracture site and the whole plate depend on the fracture gap size. In stable bone fracture, for the PPSCGF fixation plate system, maximum von Mises strain occurred at the plate's middle span above the fracture site, as illustrated in figure 9-a; while in the PPLGF and PPLGFY fixation plate systems, plates experienced strain concentration around two screw holes on the distal part of the plate (Figures 9-b and 9-c). Furthermore, due to the more significant plasticity behavior, lower stiffness, and Poisson's ratio of the PPSCGF fixation plate, it experienced more strain than the PPLGF and PPLGFY fixation plate. 


$\mathrm{D}=0.1(\mathrm{~mm})$
$\mathrm{D}=0.4(\mathrm{~mm})$
$\mathrm{D}=0.8(\mathrm{~mm})$
$\mathrm{D}=0.1(\mathrm{~mm})$
$\mathrm{D}=0.8(\mathrm{~mm})$
$\mathrm{D}=0.4(\mathrm{~mm})$
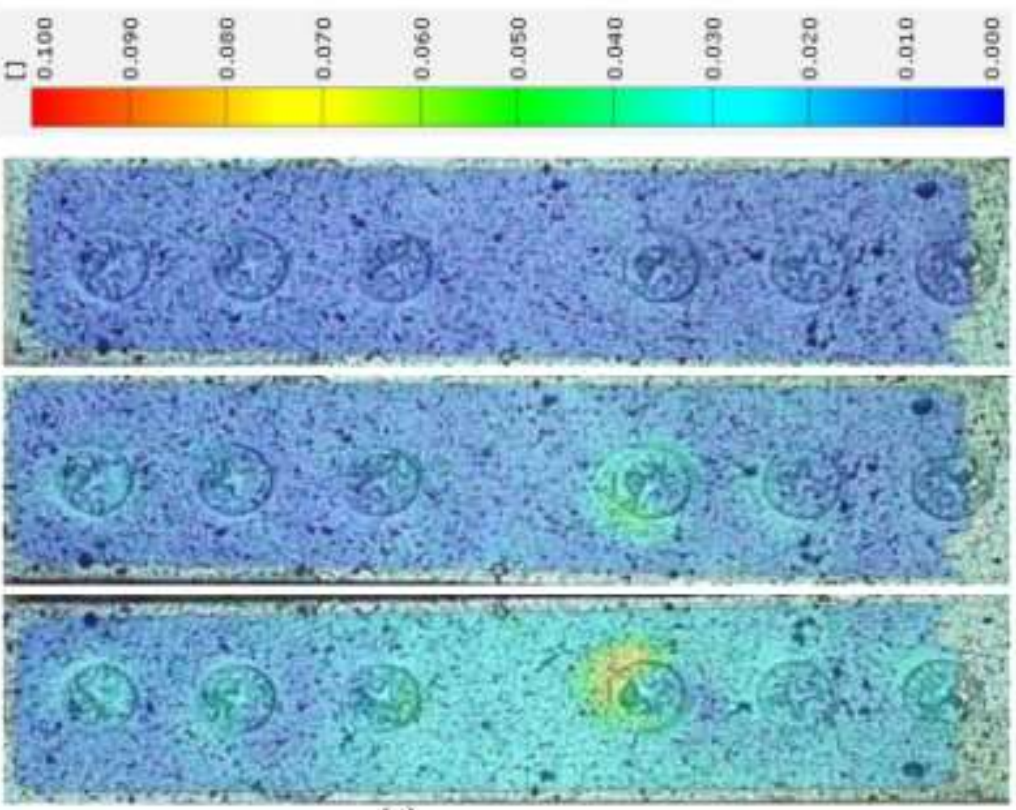

(a)
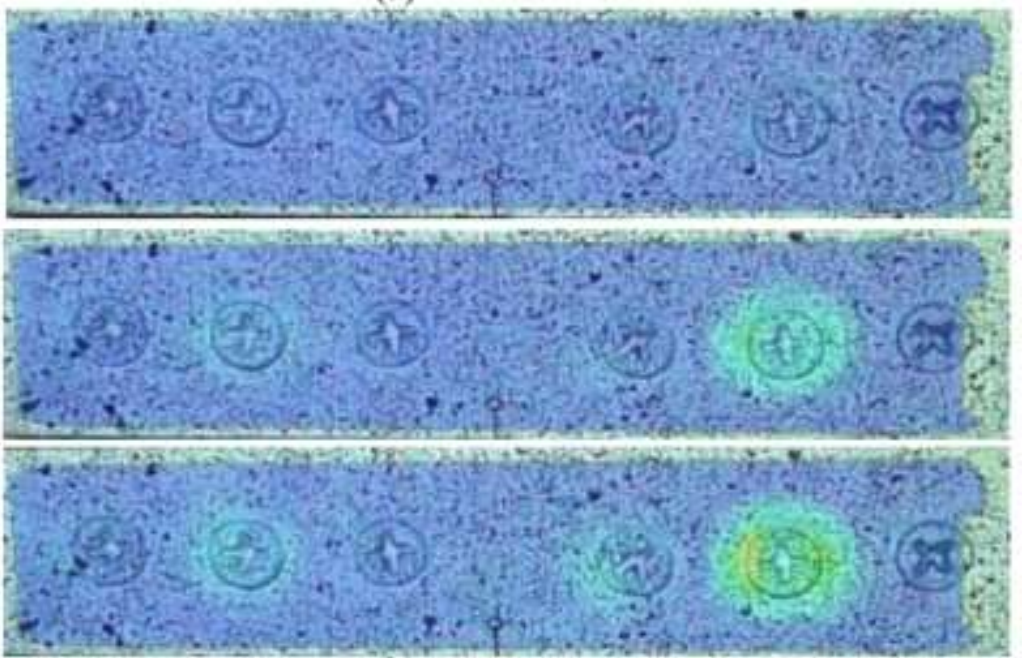

(b)
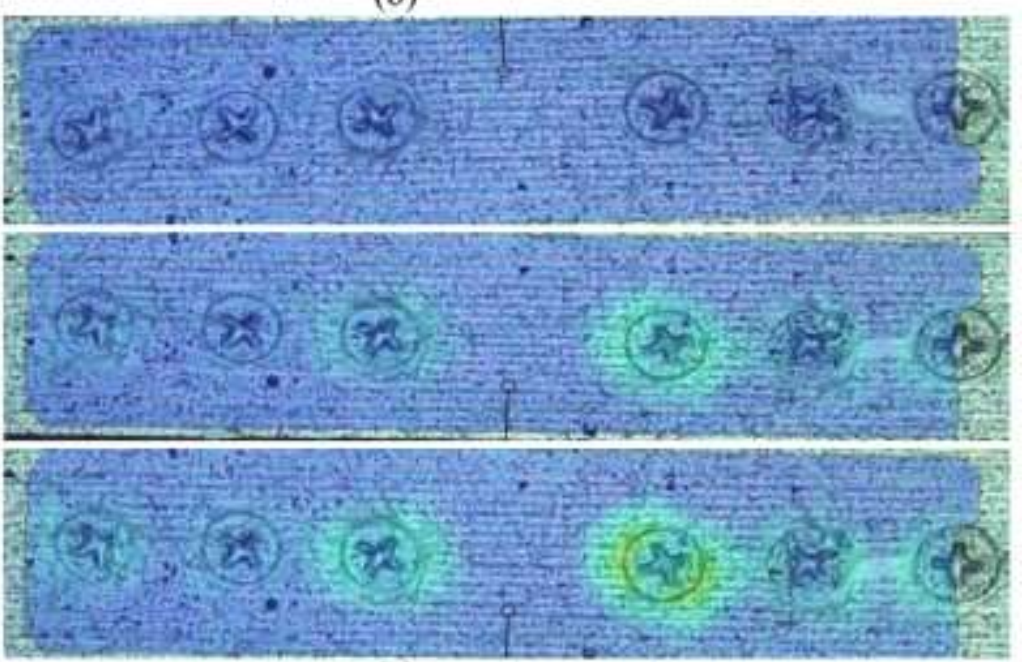

(c)

Figure 9. The equivalent von Mises strain of the different fixation plate systems in the stable bone fracture during loading at different stage of structures displacement; (a) PPSCGF, (b) PPLGF, and (c) PPLGFY. 


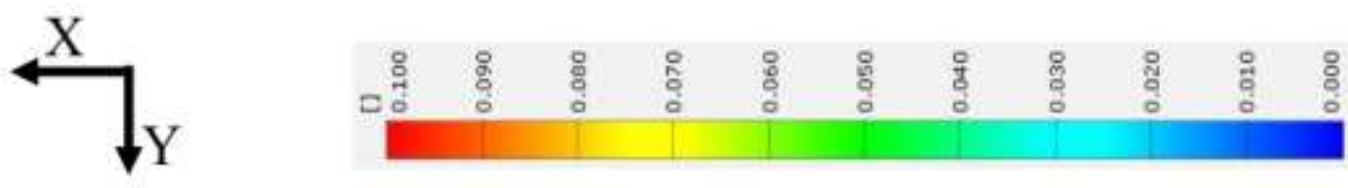

$\mathrm{D}=1(\mathrm{~mm})$

$\mathrm{D}=2(\mathrm{~mm})$

$\mathrm{D}=4(\mathrm{~mm})$

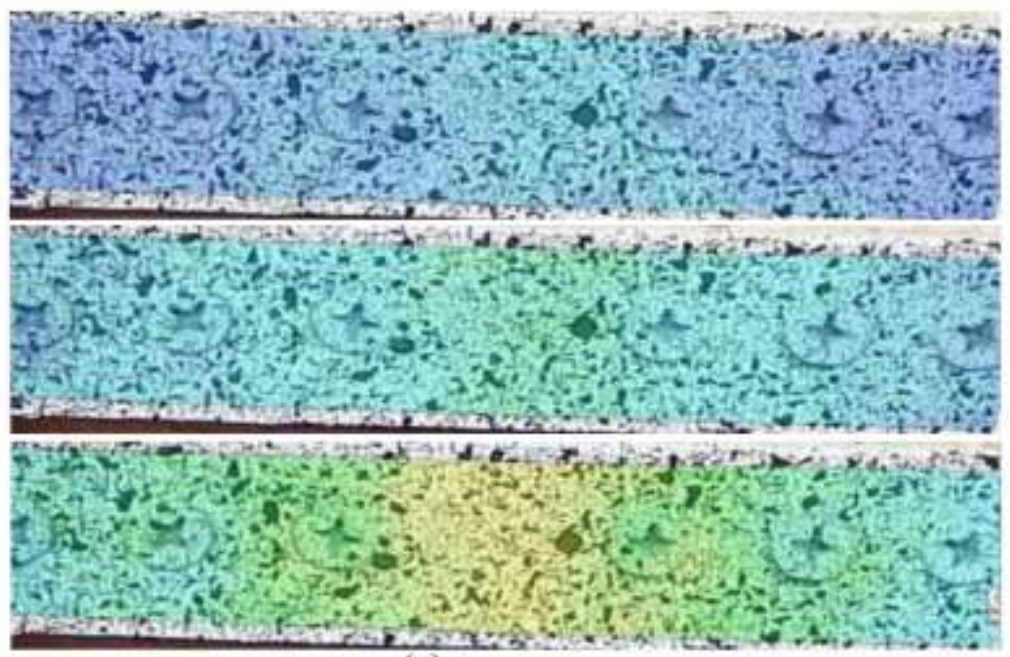

(a)

$\mathrm{D}=1(\mathrm{~mm})$

$\mathrm{D}=2(\mathrm{~mm})$

$\mathrm{D}=4(\mathrm{~mm})$
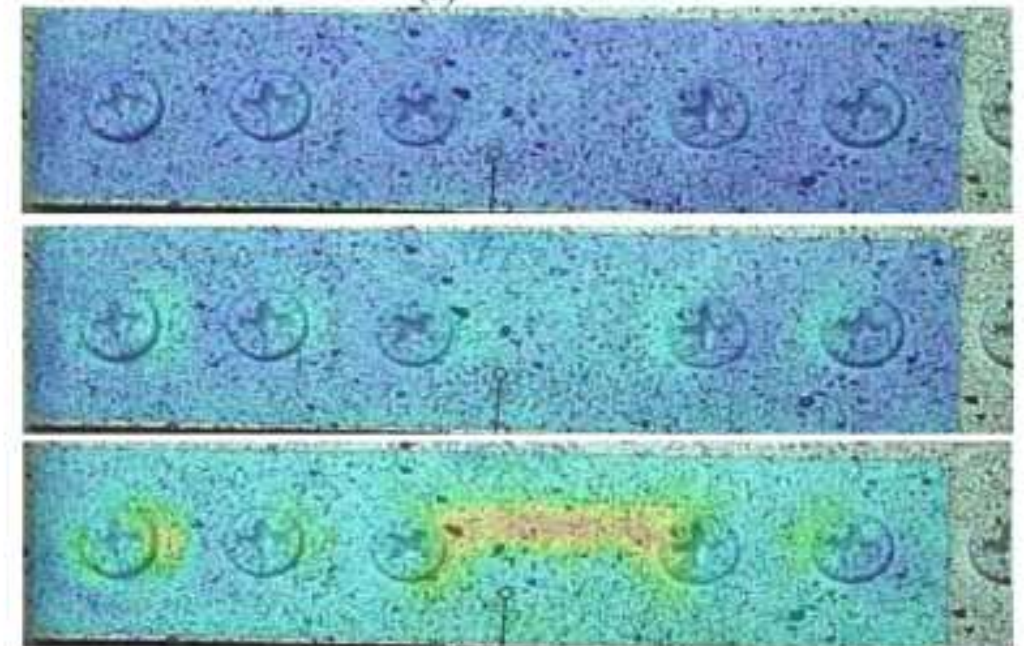

(b)

$\mathrm{D}=1(\mathrm{~mm})$

$\mathrm{D}=2(\mathrm{~mm})$

$\mathrm{D}=4(\mathrm{~mm})$

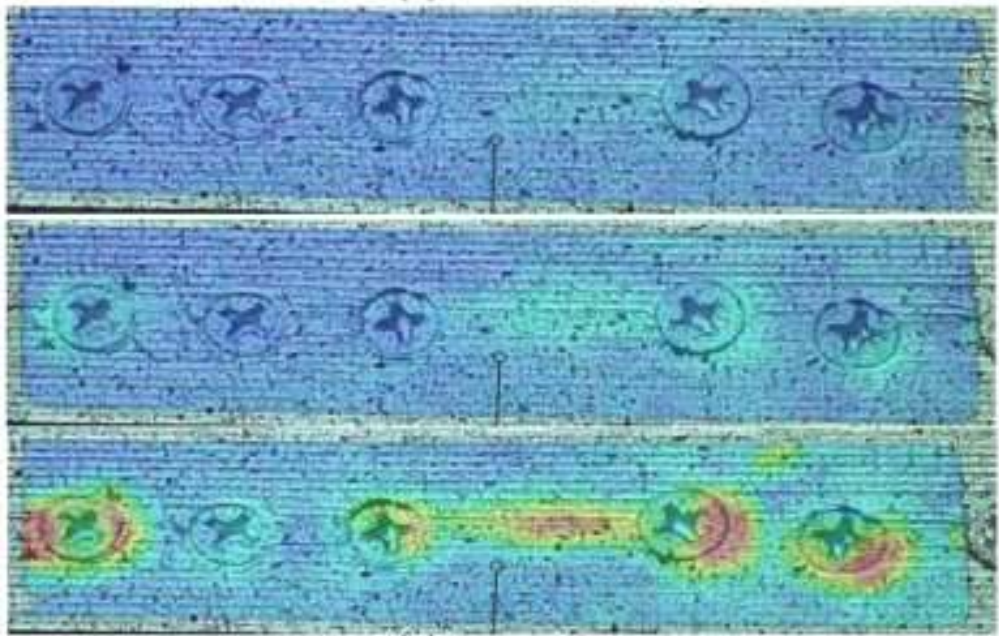

(c)

Figure 10. The equivalent von Mises strain of the different fixation plate systems in the unstable bone fracture during loading at different stage of structures displacement; (a) PPSCGF, (b) PPLGF, and (c) PPLGFY. 
Due to the increasing of the bending moment angulation of the plates, the strains intensity increases in unstable fracture conditions. Since the flexural stiffness of PPSCGF fixation plate system is less than the other fixation plates, it experiences more uniform strain distribution at the plate's middle span above the fracture site compared to others in this fracture condition (Figure 10-a). The unidirectional PPLGF and PPLGFY fixation plate systems have greater flexural stiffness, modulus, and strength than the PPSCGF one. However, due to the weaker shear properties, inadequate transverse load capacity, and interlaminar damage of these composites, the strain concentration beneath the first screw hole closed to fracture site was more significant than other areas (Figures 10-b and 10-c); consequently, it caused crack initiation, which may split the plate along the axial direction.

Generally, strain field contours along the fixation plate length revealed the occurrence of majority strain near the fracture site, and low strain contour areas (blue color) happened in the vicinity of the screws. Therefore, the fixation plate topology can be optimized by removing the lower strain areas and increasing the plate curvature. This would reduce the local strain in the mid-span to match the strain around the inner screw holes. It is believed that increasing plate flexibility using optimized fixation plates results in better fracture healing and provides satisfactory clinical results.

\subsubsection{Failure load of fixation plate systems}

It worth to be mentioned that the first abrupt drop in load-displacement curves of unstable fracture structures tests was identified as failure load. Ultimate failure was recorded just before the occurrence of catastrophic failure, which coincided with the complete drop-down of loading. As it can be seen from figure 11-a, there was no significant difference between the failure loads of the fixation plate structures.

Due to crutches usage and the existence of muscle force during fracture healing, just about one-tenth of body weight is imposed at the end of the patient tibia for 1 to 8 weeks of the 
post-surgery period [49]. Despite this fact, the load increases to twice of body weight after 8 to 12 weeks after the surgery. After that, the bodyweight increases gradually every week and reaches up to the treble of body weight in 16 weeks after the surgery [50]. According to the results, all three GF/PP composite fixation plates can bear almost twice the body weight of a person with normal weight $(70 \mathrm{~kg}$ ) during fracture healing (Figure 11-a). On the other hand, the abductor muscle group's effect, with its counteractive force, would maximize the bearing load of the fixation plate structures. Therefore, the proposed composite fixation plates can be recommended as proper candidates for orthopedic applications.

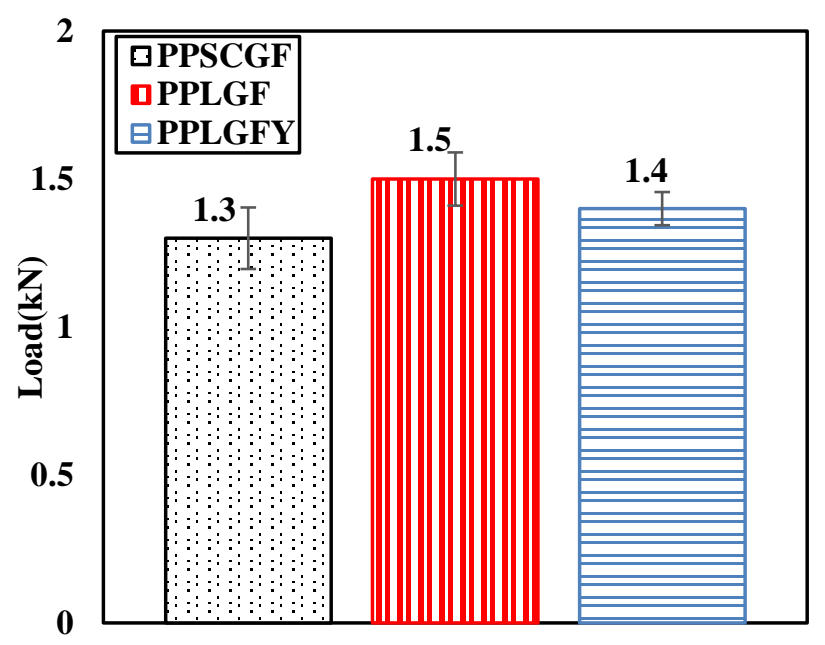

(a)

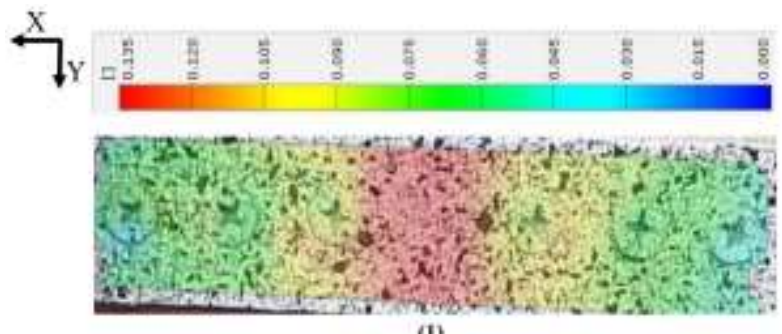

(1)

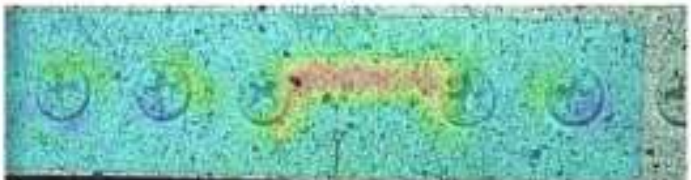

(2)

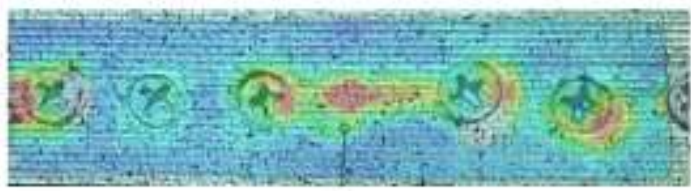

(3)

(b) 


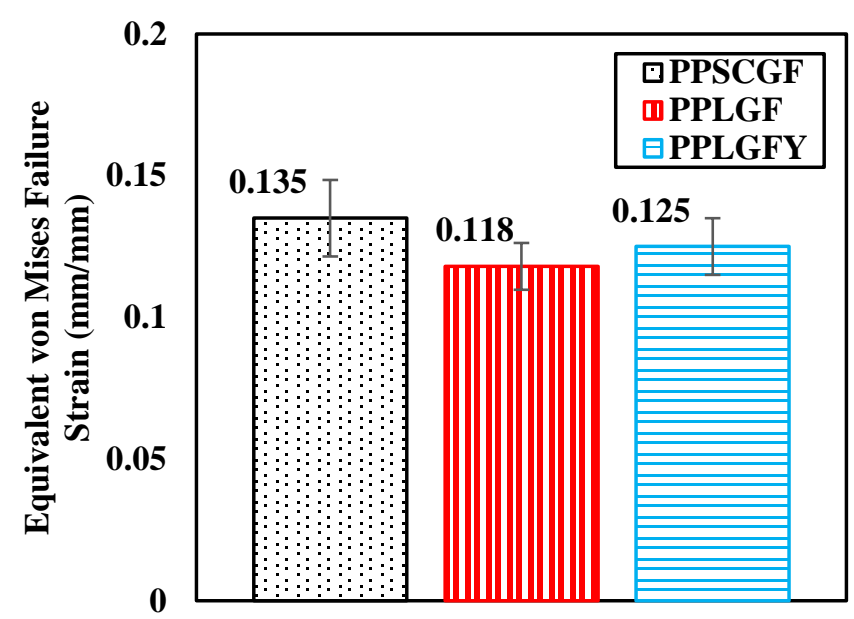

(c)

Figure 11. (a) The comparison of the composite fixation plate structures failure load in the unstable bone fracture $(\mathrm{p}<0.01)$. (b) The equivalent von Mises failure strain field of the fixation plate systems in the unstable bone fracture; (1) PPSCGF, (2) PPLGF, and (3) PPLGFY. (c) The comparison of the fixation plate systems fracture strain in the unstable bone fracture $(\mathrm{p}<0.01)$.

\subsubsection{Failure strain of fixation plate systems}

Figures 11-b and 11-c show equivalent von Mises failure strain contours and the values of composite fixation plate systems in the unstable bone fracture, respectively. The failure in the PPSCGF occurred in the middle of the plate span with a strain value of $0.135 \pm 0.015$ $\mathrm{mm} / \mathrm{mm}$; however, the failures in the PPLGF and PPLGFY occurred around the closest screw hole to the fracture site with a strain value of $0.125 \pm 0.010 \mathrm{~mm} / \mathrm{mm}$ and $0.118 \pm 0.010$ $\mathrm{mm} / \mathrm{mm}$, respectively. Thus, the screw hole intervals were the most likely areas for plate failure.

The consistent patterns of crack initiation at the bottom and top of the closest screw hole to the fracture site were observed in the PPLGF and PPLGFY fixation plate structures. These patterns are not unique to the present study and are common between biomechanical studies of composite fixation plates. Many previous studies have reported fixation failure across the closest screw hole to the fracture site $[14,16,19]$. However, the plate failure occurred in $7 \%$ of metallic fixation plates in clinical experiences [51]. Fixation loosening (resulting from bone resorption in the screw-bone interface) is the most frequent complication [52]. According to the obtained results, GF/PP composite fixation plates demonstrate better 
resistance to bending force during the fracture healing process with less chance of screw loosening and interference. Hence, they can successfully overcome the metallic biomaterials' drawbacks.

\subsubsection{Failure modes and mechanisms of fixation plate systems}

Figure 12 shows the failure modes of different fixation plates in stable and unstable bone fractures. The failure patterns depend on the gap size. Due to the strain concentration in the stable bone fracture, the local plastic deformation and crack opening happened in the PPSCGF fixation plate system (Figure 12-(a-1)), whereas the initiation of matrix cracking and fiber tearing occurred along the screw holes of the PPLGF and PPLGFY fixation plate systems (Figures 12-(b-1) and 12-(c-1)). The major failure mechanisms in the unstable bone fractures included elimination, debonding, crack opening, fiber pullout, and plastic bending. In the PPSCGF fixation plate system, although in first stage crack initiation at the closest screw hole to the fracture site occurred following plastic bending failure, eventually the system yield in a brittle manner. In the other word, the fully plastic bending and longitudinal fracture beneath the screw holes were the main failure modes of the PPSCGF fixation plate system (Figure 12-(a-2)), while the initiation of matrix cracking, fiber tearing, and edge delaminating or long splitting in glass fibers occurred in the PPLGF and PPLGFY fixation

plate systems. These failure mechanisms happened beneath the screw holes near the distal end of the bone, and also failure occurred at the entry point of the proximal screw holes (Figures 12-(b-2) and 12-(c-2)). Indeed, strain gradually had increased until strain intensity reaches a critical value, and then the catastrophic failure occurred due to the fast crack propagation from the initial crack. In the fiber bridging zone of a crack, interface debonding and frictional sliding of fiber-matrix interactions were observed. 


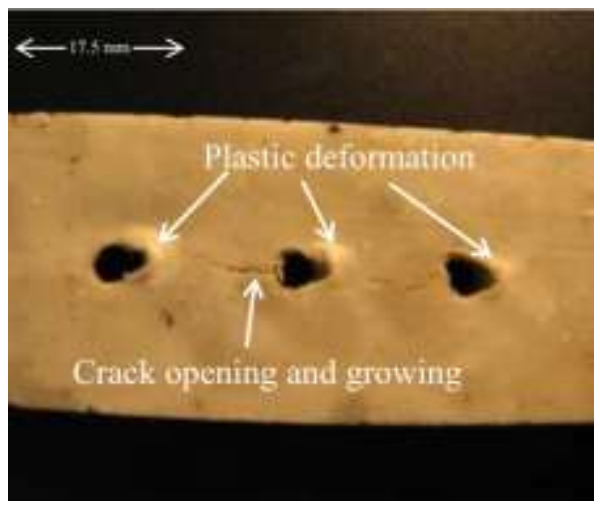

(a-1)

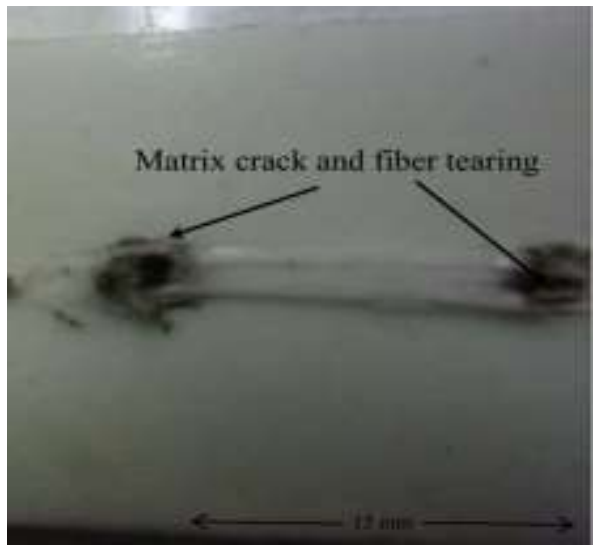

(b-1)

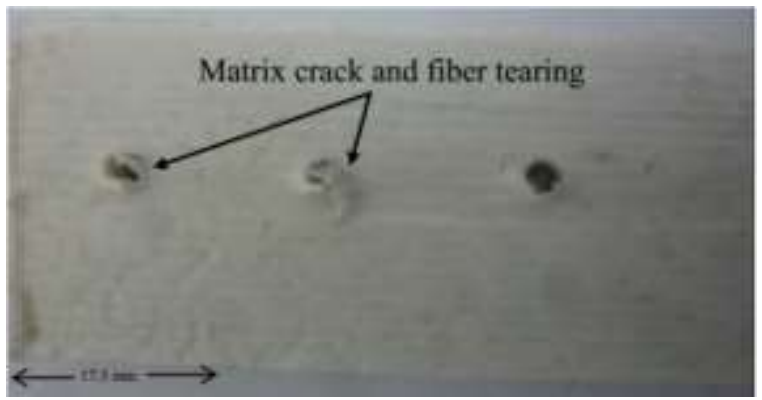

(c-1)

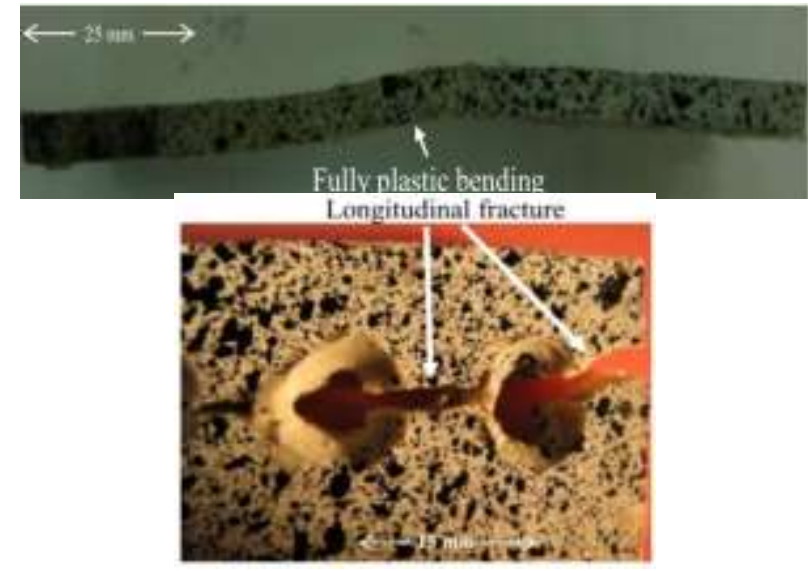

(a-2)

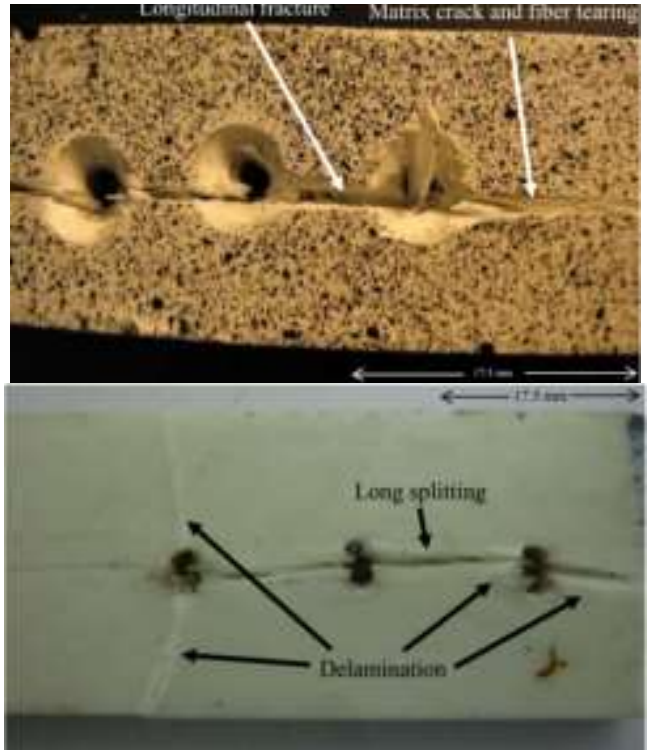

(b-2)

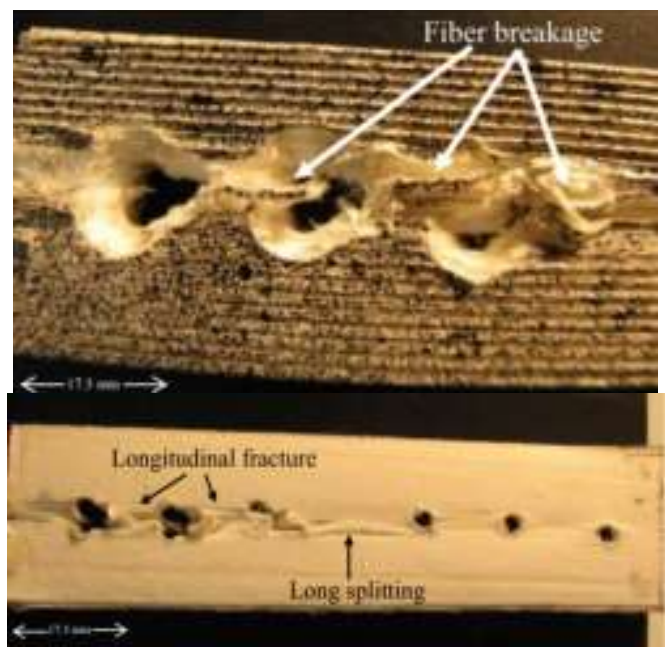

(c-2)

Figure 12. Failure modes of the (a) PPSCGF, (b) PPLGF, and (c) PPLGFY fixation plate systems in the (1) stable and (2) unstable bone fractures. 


\section{Conclusions}

In this paper, GF/PP composite fixation plates were introduced as replacements for traditional metallic ones, and the fabrication, mechanical characteristics, and in-vitro biomechanical experiments on three types of glass fiber-reinforced polypropylene internal fixations were presented. The mechanical properties of these composite plates, such as Young's, shear, and flexural modulus and strength, were obtained. Moreover, their stability, overall stiffness, and failure load and modes were investigated under axial compression loading in stable and unstable fractures. Furthermore, the strain field and the failure strain of these fixation plates were obtained using the digital image correlation (DIC) technique. According to the axial compression loading results, all three GF/PP composite fixation plates can bear almost twice of body weight of a person with normal weight $(70 \mathrm{~kg})$ during the fracture healing process. Their significant flexibility compared to conventional metallic plates elucidates their potential as substitutes for metallic plates. Therefore, these new PPLGF and PPLGFY composite plates, with similar stiffness and strength to long human bones, could be used in femoral shaft and tibia fractures while the PPSCGF composite fixation plate could be an interesting new fixation for small bone fractures.

In summary, all the suggested composite fixation materials not only provide sufficient primary stability for fractured bone segments, but also allow adequate interfragmentary motion to promote secondary bone healing. Furthermore, the proposed composite fixation plates, by increasing bone resistance to loosening, can overcome the high failure rate of bone fractures in clinical applications. However, additional in-vitro and in-vivo studies are needed for definitive conclusions. 


\section{Compliance with ethical standards}

Conflict of interest: The authors declare that there is no conflict of interest.

Ethical Approval: This study does not contain any studies with human or animal subjects performed by any of the authors.

\section{References}

[1] Uhthoff HK, Poitras P, Backman DS. Internal plate fixation of fractures: short history and recent developments. Journal of Orthopaedic Science 2006; 11: 118-126.

[2] Chen Q, Thouas GA. Metallic implant biomaterials. Materials Science and Engineering: R: Reports 2015; 87: 1-57.

[3] Ahmad M, Nanda R, Bajwa AS, et al. Biomechanical testing of the locking compression plate: when does the distance between bone and implant significantly reduce construct stability?. Injury 2007; 38: 358-364.

[4] Bottlang M, Doornink J, Fitzpatrick DC, et al. Far cortical locking can reduce stiffness of locked plating constructs while retaining construct strength. The Journal of Bone and Joint Surgery 2009; 91: 1985.

[5] Bottlang M, Doornink J, Lujan TJ, et al. AAOS supplement selected scientific exhibits: effects of construct stiffness on healing of fractures stabilized with locking plates. The Journal of Bone and Joint Surgery 2010; 92: 12.

[6] Moazen M, Leonidou A, Pagkalos J, et al. Application of far cortical locking technology in periprosthetic femoral fracture fixation: a biomechanical study. The Journal of arthroplasty 2016; 31: 1849-1856.

[7] Yánez A, Carta JA, Garcés G. Biomechanical evaluation of a new system to improve screw fixation in osteoporotic bones. Medical engineering \& physics 2010; 32: 532-541.

[8] Tsai S, Fitzpatrick DC, Madey SM, et al. Dynamic locking plates provide symmetric axial dynamization to stimulate fracture healing. Journal of Orthopaedic Research 2015; 33: 12181225 .

[9] Fitzpatrick D, Hansen K, Madey S, et al. The use of far cortical locking constructs for fixation of periprosthetic fractures. Techniques in Orthopaedics 2013; 28: 260-264. 
[10] Mehboob H, Chang SH. Application of composites to orthopedic prostheses for effective bone healing: A review. Composite Structures 2014; 118: 328-341.

[11] Ramakrishna S, Mayer J, Wintermantel E, et al. Biomedical applications of polymercomposite materials: a review. Composites science and technology 2001; 61: 1189-1224.

[12] Tonino AJ, Davidson CL, Klopper PJ, et al. Protection from stress in bone and its effects. Experiments with stainless steel and plastic plates in dogs. The Journal of bone and joint surgery 1976; 58: 107-113.

[13] Gillett N, Brown SA, Dumbleton JH, et al. The use of short carbon fibre reinforced thermoplastic plates for fracture fixation. Biomaterials 1985; 6: 113-121.

[14] Bagheri ZS, Tavakkoli Avval P, Bougherara H, et al. Biomechanical analysis of a new carbon fiber/flax/epoxy bone fracture plate shows less stress shielding compared to a standard clinical metal plate. Journal of biomechanical engineering 2014; 136.

[15] Mudrick CA, Owen JR, Wayne JS, et al. Unicortical PEEK inset locking fixation for metacarpal fractures: a biomechanical study. European Journal of Orthopaedic Surgery \& Traumatology 2014; 24: 1415-1420.

[16] Chakladar ND, Harper LT, Parsons AJ. Optimisation of composite bone plates for ulnar transverse fractures. Journal of the mechanical behavior of biomedical materials 2016; 57: 334-346.

[17] Yeon YK, Park HS, Lee JM, et al. New concept of 3D printed bone clip (polylactic acid/hydroxyapatite/silk composite) for internal fixation of bone fractures. Journal of Biomaterials science, Polymer edition. 2018; 29: 894-906.

[18] Qiao B, Zhou D, Dai Z, et al. Bone Plate Composed of a Ternary Nanohydroxyapatite/Polyamide 66/Glass Fiber Composite: Biocompatibility In Vivo and Internal Fixation for Canine Femur Fractures. Advanced Functional Materials 2019; 29: 1808738.

[19] Rendenbach C, Steffen C, Sellenschloh K, et al. Patient specific glass fiber reinforced composite versus titanium plate: a comparative biomechanical analysis under cyclic dynamic loading. Journal of the mechanical behavior of biomedical materials 2019; 91: 212-219.

[20] Park SW, Yoo SH, An ST, et al. Material characterization of glass/polypropylene composite bone plates according to the forming condition and performance evaluation under a simulated human body environment. Composites Part B: Engineering 2012; 43: 1101-1108. 
[21] Kabiri A, Liaghat G, Alavi F, et al. Glass fiber/polypropylene composites with potential of bone fracture fixation plates: Manufacturing process and mechanical characterization. Journal of Composite Materials 2020; 54: 4903-4919.

[22] Brydone AS, Meek D, Maclaine S. Bone grafting, orthopaedic biomaterials, and the clinical need for bone engineering. Proceedings of the Institution of Mechanical Engineers, Part H: Journal of Engineering in Medicine 2010; 224: 1329-1343.

[23] Mondal S, Ghosh R. Effects of implant orientation and implant material on tibia bone strain, implant-bone micromotion, contact pressure, and wear depth due to total ankle replacement. Proceedings of the Institution of Mechanical Engineers, Part H: Journal of Engineering in Medicine 2019; 233: 318-331.

[24] Singh J, Kaur T, Singh N, et al. Biological and mechanical characterization of biodegradable carbonyl iron powder/polycaprolactone composite material fabricated using three-dimensional printing for cardiovascular stent application. Proceedings of the Institution of Mechanical Engineers, Part H: Journal of Engineering in Medicine 2020; 234: 975-987.

[25] Hertel R, Eijer H, Meisser A, et al. Biomechanical and biological considerations relating to the clinical use of the Point Contact-Fixator-evaluation of the device handling test in the treatment of diaphyseal fractures of the radius and/or ulna. Injury 2001; 32: 10-4.

[26] Hedayati SK, Behravesh AH, Hasannia S, et al. 3D printed PCL scaffold reinforced with continuous biodegradable fiber yarn: A study on mechanical and cell viability properties. Polymer Testing 2020; 83: 106347.

[27] Zdero R. Experimental methods in orthopaedic biomechanics. Academic Press 2016.

[28] Kabiri A, Liaghat G, Alavi F. Biomechanical evaluation of glass fiber/polypropylene composite bone fracture fixation plates: Experimental and numerical analysis. Computers in Biology and Medicine 2021; 132: 104303.

[29] Sutton MA, Orteu JJ, Schreier H. Image correlation for shape, motion and deformation measurements: basic concepts, theory and applications. Springer Science \& Business Media 2009.

[30] Felipe-Sese L, Siegmann P, Diaz FA, et al. Simultaneous in-and-out-of-plane displacement measurements using fringe projection and digital image correlation. Optics and Lasers in Engineering 2014; 52: 66-74.

[31] Huda MS, Drzal LT, Mohanty AK, et al. Effect of fiber surface-treatments on the properties of laminated biocomposites from poly (lactic acid)(PLA) and kenaf fibers. Composites science and technology 2008; 68: 424-432. 
[32] Aydin E, Planell JA, Hasirci V. Hydroxyapatite nanorod-reinforced biodegradable poly (L-lactic acid) composites for bone plate applications. Journal of Materials Science: Materials in Medicine 2011; 22: 2413-2427.

[33] Li X, Chu CL, Liu L, et al. Biodegradable poly-lactic acid based-composite reinforced unidirectionally with high-strength magnesium alloy wires. Biomaterials 2015; 49: 135-144.

[34] Jiang G, Evans ME, Jones IA, et al. Preparation of poly ( $\varepsilon$-caprolactone)/continuous bioglass fibre composite using monomer transfer moulding for bone implant. Biomaterials 2005; 26: 2281-2288.

[35] Kobayashi HY, Brauer DS, Rüssel C. Mechanical properties of a degradable phosphate glass fibre reinforced polymer composite for internal fracture fixation. Materials Science and Engineering: C 2010; 30: 1003-1007.

[36] Ahmed I, Jones IA, Parsons AJ, et al. Composites for bone repair: phosphate glass fibre reinforced PLA with varying fibre architecture. Journal of Materials Science: Materials in Medicine 2011; 22: 1825-1834.

[37] Charlet K, Jernot JP, Gomina M, et al. Mechanical properties of flax fibers and of the derived unidirectional composites. Journal of Composite Materials 2010; 44: 2887-2896.

[38] Gning PB, Liang S, Guillaumat L, et al. Influence of process and test parameters on the mechanical properties of flax/epoxy composites using response surface methodology. Journal of materials science 2011; 46: 6801-6811.

[39] Lamy B, Baley C. Stiffness prediction of flax fibers-epoxy composite materials. Journal of materials science letters 2000; 19: 979-980.

[40] Manteghi S, Mahboob Z, Fawaz Z, et al. Investigation of the mechanical properties and failure modes of hybrid natural fiber composites for potential bone fracture fixation plates. Journal of the mechanical behavior of biomedical materials 2017; 65: 306-316.

[41] Fiore VI, Di Bella G, Valenza A. Glass-basalt/epoxy hybrid composites for marine applications. Materials \& Design 2011; 32: 2091-2099.

[42] Khanam PN, Khalil HA, Jawaid M, et al. Sisal/carbon fibre reinforced hybrid composites: tensile, flexural and chemical resistance properties. Journal of Polymers and the Environment 2010; 18: 727-733.

[43] Moritz N, Strandberg N, Zhao DS, et al. Mechanical properties and in vivo performance of load-bearing fiber-reinforced composite intramedullary nails with improved torsional strength. Journal of the mechanical behavior of biomedical materials 2014; 40: 127-139. 
[44] Siddiqui FS, Shah S, Nicayenzi B, et al. Biomechanical analysis using infrared thermography of a traditional metal plate versus a carbon fibre/epoxy plate for Vancouver B1 femur fractures. Proceedings of the Institution of Mechanical Engineers, Part H: Journal of Engineering in Medicine 2014; 228: 107-113.

[45] Talbot M, Zdero R, Garneau D, et al. Fixation of long bone segmental defects: a biomechanical study. Injury 2008; 39: 181-186.

[46] Dubov A, Kim SY, Shah S, et al. The biomechanics of plate repair of periprosthetic femur fractures near the tip of a total hip implant: the effect of cable-screw position. Proceedings of the Institution of Mechanical Engineers, Part H: Journal of Engineering in Medicine 2011; 225: 857-865.

[47] Ebrahimi H, Rabinovich M, Vuleta V, et al. Biomechanical properties of an intact, injured, repaired, and healed femur: an experimental and computational study. Journal of the mechanical behavior of biomedical materials 2012; 16: 121-135.

[48] Simkin A, Robin G. The mechanical testing of bone in bending. Journal of biomechanics 1973; 6: 31-39.

[49] Kim HJ, Kim SH, Chang SH. Finite element analysis using interfragmentary strain theory for the fracture healing process to which composite bone plates are applied. Composite structures 2011; 93: 2953-2962.

[50] Son DS, Chang SH. The simulation of bone healing process of fractured tibia applied with composite bone plates according to the diaphyseal oblique angle and plate modulus. Composites Part B: Engineering 2013; 45: 1325-1335.

[51] Riemer BL, Butterfield SL, Burke CJ, et al. Immediate plate fixation of highly comminuted femoral diaphyseal fractures in blunt polytrauma patients. Orthopedics 1992; 15: 907-916.

[52] Comte P, Straumann F. Influence of unoccupied holes on the fatigue behaviour of bone fixation plates. In Biomechanics: Current Interdisciplinary Research 1985: 459-464. 